\title{
Endogenous testosterone correlates with parochial altruism depending on decision strategy in relation to costly punishment
}

\author{
Luise Reimers $^{\text {Equal first author, }{ }^{1} \text {, Eli Kappo }}{ }^{1}$, Lucas Stadler ${ }^{1}$, Mostafa Yaqubi ${ }^{1}$, Esther K Diekhof ${ }^{\text {Corresp. Equal first author, } 1}$ \\ ${ }^{1}$ Faculty of Mathematics, Informatics and Natural Sciences, Department of Biology, Institute of Zoology, Neuroendocrinology and Human Biology Unit, \\ Universität Hamburg, Hamburg, Germany \\ Corresponding Author: Esther K Diekhof \\ Email address: esther.diekhof@uni-hamburg.de
}

Testosterone plays a key role in shaping human social behavior. Recent findings have linked testosterone to altruistic behavior in economic decision tasks depending on group membership and intergroup competition. The preferential treatment of ingroup members, while aggression and discrimination is directed towards outgroup members, has been referred to as parochial altruism.

Here we investigated in two consecutive studies, whether testosterone is associated with parochial altruism depending on individual tendency for costly punishment. In the first study, 61 men performed a single-shot ultimatum game (UG) in a minimal group context, in which they interacted with members of an ingroup and outgroup. In the second study, 34 men performed a single-shot UG in a more realistic group context, in which they responded to the proposals of supporters of six political parties during the German election year 2017. Political parties varied in their social distance to the participants' favorite party as indicated by an individual ranking. Participants of study 2 also performed a cued recall task, in which they had to decide whether they had already encountered a face during the previous UG (old-new decision). In order to make the UG data of study 2 most comparable to the data of study 1, the rejection rates of several parties were combined according to the social distance ranking they achieved. Parties ranked 1 to 3 formed the relatively close and favored 'ingroup' that shared similar political values with the participant (e.g., left wing parties), while the 'outgroup' consisted of parties ranked from 4 to 6 with more distant or even antagonistic political views (e.g., conservative to right wing parties). In both studies, results showed a parochial pattern with higher rejection rates made in response to outgroup compared to ingroup offers. Interestingly, across studies higher salivary testosterone was associated with higher rejection rates related to unfair outgroup offers in comparison to the unfair offers made by ingroup members.

The present findings suggest that latent intergroup biases during decision-making may be positively related to endogenous testosterone. Similar to previous evidence that already indicated a role of testosterone in shaping male parochial altruism in male soccer fans, these data underscore the general, yet rather subtle role of male testosterone also in other social settings. 
1

2

3

4

5

\section{6}

7

8

9

10

11

12

14

15

16

17

18

19

20

21

22

23

24

25

26

27

28

29

30

31

32

33

34

35

36
Luise Reimers ${ }^{1, *}$, Eli Kappo ${ }^{1}$, Lucas Stadler ${ }^{1}$, Mostafa Yaqubi ${ }^{1}$, Esther K. Diekhof ${ }^{1, *}$

${ }^{1}$ Faculty of Mathematics, Informatics and Natural Sciences, Department of Biology, Institute of Zoology, Neuroendocrinology and Human Biology Unit, Universität Hamburg, Hamburg, Germany

*These authors contributed equally

Corresponding author:

Prof. jun. Dr. Esther Diekhof

University of Hamburg

Zoological Institute

Neuroendocrinology Unit

Martin-Luther-King Platz 3

D-20146 Hamburg/ Germany

Tel.: +49-40-42838-3931

Email: esther.diekhof@uni-hamburg.de 


\section{Abstract}

38

39 Testosterone plays a key role in shaping human social behavior. Recent findings have linked 40 testosterone to altruistic behavior in economic decision tasks depending on group membership 41 and intergroup competition. The preferential treatment of ingroup members, while aggression 42 and discrimination is directed towards outgroup members, has been referred to as parochial 43 altruism.

44 Here we investigated in two consecutive studies, whether testosterone is associated with parochial altruism depending on individual tendency for costly punishment. In the first study, 61 men performed a single-shot ultimatum game (UG) in a minimal group context, in which they interacted with members of an ingroup and outgroup. In the second study, 34 men performed a single-shot UG in a more realistic group context, in which they responded to the proposals of supporters of six political parties during the German election year 2017. Political parties varied in their social distance to the participants' favorite party as indicated by an individual ranking.

51 Participants of study 2 also performed a cued recall task, in which they had to decide whether 52 they had already encountered a face during the previous UG (old-new decision). In order to make 53 the UG data of study 2 most comparable to the data of study 1 , the rejection rates of several 54 parties were combined according to the social distance ranking they achieved. Parties ranked 1 to 553 formed the relatively close and favored 'ingroup' that shared similar political values with the 56 participant (e.g., left wing parties), while the 'outgroup' consisted of parties ranked from 4 to 6 57 with more distant or even antagonistic political views (e.g., conservative to right wing parties).

58 In both studies, results showed a parochial pattern with higher rejection rates made in response to 59 outgroup compared to ingroup offers. Interestingly, across studies higher salivary testosterone 
60

61

62

63

64

65

66

67

68

69

70

71

72

73

74

75

76

77 have to engage in hostile acts with outsiders, and are willingly to do so despite negative

was associated with higher rejection rates related to unfair outgroup offers in comparison to the unfair offers made by ingroup members.

The present findings suggest that latent intergroup biases during decision-making may be positively related to endogenous testosterone. Similar to previous evidence that already indicated a role of testosterone in shaping male parochial altruism in male soccer fans, these data underscore the general, yet rather subtle role of male testosterone also in other social settings.

\section{Introduction}

Humans display a large extent of prosocial behaviors such as cooperation and altruism. At the same time, the human history of conflicts and wars is unparalleled. This supposedly inconsistent behavior of ingroup favoritism and outgroup hostility has recently been referred to as parochial altruism (Choi and Bowles 2007). A behavior is thereby defined as altruistic if it incurs personal costs without direct benefits or only minimal benefits for the actor, but happens to benefit another person or a group of people (in case of parochial altruism this would be the ingroup). For example, in order to protect members of the ingroup against outgroup threat individuals may consequences like death or mutilation. Empirical evidence for parochial altruism comes from

79 several studies that used economic decision tasks to emulate real-world situations in which 80 limited resources are unequally distributed between competing human groups (Baumgartner et 81 al. 2012; Bernhard, Fischbacher, and Fehr 2006; Diekhof, Wittmer, and Reimers 2014;

82 Fershtman and Gneezy 2001; Goette et al. 2012; Kubota et al. 2013; Reimers and Diekhof 2015). 83 For instance, members of different indigenous language groups in Papua New Guinea have been 84 shown to display a strong ingroup bias by punishing norm violators that treated members of their 
85 own group unfairly more often compared to situations, in which the "victim" of the unequal

86 share was an outgroup member (Bernhard, Fischbacher, and Fehr 2006). In addition, this ingroup

87 bias seemed to be accompanied by a stronger tendency towards outgroup hostility in contexts

88 that involved a competition between groups. Accordingly, in such a group competition context,

89 army platoon members punished members of other platoons more harshly than in a neutral

90 decision context, and even if the outgroup members were cooperative (Goette et al. 2012). It thus

91 appears as if humans have a tendency for both ingroup favoritism and outgroup hostility that

92 may be explained with the prevalent intergroup conflicts in human ancestry. Since cooperation

93 within the own group and successfully competing against outgroups was crucial in terms of

94 survival, these conflicts have been proposed to have led to the evolution of both altruism and

95 parochialism (Bowles 2009; Choi and Bowles 2007).

96 Accumulating evidence has previously linked testosterone to economic decision making in social

97 interactions, yet studies mostly revealed inconsistent results. For instance, some studies found

98 that testosterone was associated with increased fairness preference and thus higher rejection rates

99 in response to unfair proposals made in the context of an ultimatum game (UG) (Burnham 2007;

100 Dreher et al. 2016; Eisenegger et al. 2010; Mehta and Beer 2010; Diekhof, Wittmer, and Reimers

101 2014), which has been interpreted as an act of altruistic punishment as it involves the loss of the

102 offered share. Others found the opposite, namely that testosterone administration may be related

103 to increased greediness and selfishness as well as a reduced fairness preference in the UG, which

104 was reflected by either reduced punishment of violations of the fairness norm or reduced

105 generosity when being in the role of the UG proposer (Kopsida et al. 2016; Zak et al. 2009).

106 Finally, some studies found no effect at all (Cueva et al. 2017; Zethraeus et al. 2009). However,

107 the above-mentioned studies differed in their methodological approach: some investigated 
108 endogenous testosterone effects (Burnham 2007; Mehta and Beer 2010; Diekhof, Wittmer, and

109 Reimers 2014), while others tested the effect of testosterone administration (Cueva et al. 2017;

110 Eisenegger et al. 2010; Kopsida et al. 2016; Zak et al. 2009; Zethraeus et al. 2009). Moreover,

111 samples consisted either of men (Burnham 2007; Cueva et al. 2017; Dreher et al. 2016; Zak et al.

112 2009; Diekhof, Wittmer, and Reimers 2014), or women (Eisenegger et al. 2010; Zethraeus et al.

113 2009) or were mixed (Kopsida et al. 2016; Mehta and Beer 2010). This made it difficult to

114 discern the actual effect of testosterone on economic decisions in the UG, and well-designed

115 replication studies are currently lacking.

116

117 As to the mechanism underlying parochial altruism, testosterone has recently been proposed to

118 be an important mediator of decision-making in the UG and related economic decision tasks that

119 involved an intergroup factor (Diekhof, Wittmer, and Reimers 2014; Reimers, Büchel, and

120 Diekhof 2017; Reimers and Diekhof 2015). One recent study investigated the behavioral effects

121 of endogenous testosterone by accounting for group membership and intergroup competition.

122 Male soccer fans played the UG against other soccer fans of either their own favorite team

123 (ingroup) or of other teams of varying enmity and social distance (outgroups) (Diekhof, Wittmer,

124 and Reimers 2014). In the UG two players bargain about how to split an initial endowment

125 (Güth, Schmittberger, and Schwarze 1982). Soccer fans with high testosterone levels offered

126 more points to the ingroup and also rejected rather fair offers ( $40 \%$ of initial endowment), when

127 these were made by an outgroup in a competitive relative to a neutral decision context, in which

128 an additional group reward could be acquired (Diekhof, Wittmer, and Reimers 2014). A similar

129 pattern of increased ingroup cooperation in the face of intensified intergroup competition was

130 found in a prisoner's dilemma, another economic decision task measuring cooperation rates 
131 (Reimers and Diekhof 2015). Moreover, a recent neuroimaging study has provided first evidence

132 for testosterone's action in the brain in a sample of male soccer fans playing the UG (Reimers,

133 Büchel, and Diekhof 2017). The results indicate dissociable testosterone-brain correlations

134 depending on individual tendency for costly punishment. In individuals with a more selfish (i.e.,

135 economically rational) strategy and lower rejection rates in response to unfair offers of ingroup

136 members, testosterone was positively correlated with activity in the anterior insula. In the context

137 of the UG, the anterior insula has been implicated in processing of negative emotions and norm

138 violations (Civai et al. 2012; Sanfey et al. 2003), as well as with positive emotional affect in

139 other contexts (e.g., Hennenlotter et al. 2005). Therefore, the positive association between

140 testosterone and insular activation despite lower rejection rates could be interpreted as the

141 voluntary decision against sanctioning an unfair ingroup member, thus supposedly reflecting

142 increased ingroup favoritism in a social dilemma situation (Reimers, Büchel, and Diekhof 2017).

143 In inequity averse individuals (i.e., subjects with strong fairness preference and generally

144 enhanced rejection rates) high testosterone was predictive of increased activity in ventromedial

145 prefrontal regions, which have previously been associated with monitoring of subjective reward

146 value (Amodio and Frith 2006; Plassmann et al. 2008). Despite similar rejection rates for ingroup

147 and outgroup offers, this was observed in response to unfair outgroup proposers only, thus

148 supposedly reflecting the increased reward value of sanctioning a norm-violating outgroup

149 member. Interestingly, the selfish players also showed a stronger tendency towards parochial

150 altruism (higher rejection rates in response to unfair outgroup than ingroup offers) even in

151 absence of an intergroup competition. Based on these observations we assume that the

152 inconsistent findings of the previous studies of other researcher, as described above, may be

153 explained by the fact, that testosterone is not associated with unfairness perception per se, but 
154 promotes the fine-tuning of economic decisions in an intergroup situation. In that way

155 testosterone may be rather linked to ingroup favoritism and/or outgroup hostility, the two

156 characteristics of parochialism altruism, as indicated by the converging evidence from our own

157 studies. The above-mentioned studies tested male soccer fans, who maintain long-term rivalries

158 to other teams and show a strong, genuine feeling of group affiliation that might even compare to

159 a 'tribal identity' (Vugt and Park 2010). As such, soccer fans represent a natural social group

160 with a strong emotional involvement that is suitable to study parochial altruism (Weisel and

161 Böhm 2015). Here, we investigated whether testosterone similarly affects parochial altruism in

162 artificially created groups (study 1) and in a more natural context of political party supporters

163 during the election year 2017 (study 2). This was based on two reasons: first, we wanted to

164 examine whether the link between testosterone and parochialism is stable enough to be observed

165 in two independent groups and in different social settings, i.e., whether the association found

166 between testosterone in the minimal group study 1 could also be observed in the more realistic

167 social setting of study 2 . And second, the group commitment of soccer fans as well as the enmity

168 to other soccer teams can vary with the current position of the admired team in the league and the

169 ongoing team competition can create a stressor, which is often observed in unstable social

170 hierarchies, and could have potentially altered or obscured subtle parochial tendencies in our

171 previous studies. By assessing the present participants in two rather stable group settings, i.e.,

172 either in the minimal group setting with a fixed group association (study 1) or during the German

173 election year (study 2), we tried to control for these interfering variables.

174 In the first study, we conducted the UG experiment with men that were divided into two arbitrary

175 groups according to their behavioral performance in a reaction time task that was completed

176 directly before the UG. In the second study, we questioned male participants about their political 
177 orientation using a ranking procedure through which we individually identified the favorite

178 political party as well as the one most distant to the participant. Moreover, since memory for

179 uncooperative group members was found to be enhanced in previous studies (Bell et al. 2012;

180 Bell and Buchner 2009, 2012; Hechler, Neyer, and Kessler 2016; Howard and Rothbart 1980),

181 we assessed cued recall performance in a surprise face memory task (old-new decision) that used

182 same number of new faces that were used to represent players in the UG. With this we wanted to 183 assess whether there was indeed a memory advantage for ingroup members who showed

184 schema-incongruent behavior in the UG, i.e., a norm violation through an unfair proposal, as 185 suggested previously (e.g., Hechler, Neyer, and Kessler 2016). Moreover, we wanted to explore 186 whether enhanced memory for ingroup norm violators might by associated with testosterone, 187 since our previous neuroimaging study showed that there may be a link between testosterone and 188 insular brain activation in this context (Reimers, Büchel \& Diekhof, 2017). Based on the results 189 of our previous studies with soccer fans, we hypothesized that subjects with a high endogenous 190 testosterone level would display enhanced parochial altruism in both studies.

191

192

193

194

195

196

197

198

199

200

201

\section{Material and Methods}

\subsection{Study 1}

\subsubsection{Participants of study 1}

61 healthy male students (mean age \pm SD: $24.95 \pm 4.28$ years) participated in this study. The participants were recruited via online advertisement on a campus website and by word of mouth. Only subjects that reported no drug or alcohol abuse, no chronic or psychiatric illness and did not 
202 take any form of medication, especially hormones, were included in this study. They were paid a

203 show-up fee of $10 €$ for participation and were told that they could win even more money (up to

$2045 €$ ) depending on their performance. This study was approved by the local ethics committee

205 (Aerztekammer Hamburg; Ethical Application Ref: PV3948). All subjects gave written informed 206 consent prior to participation.

207

208

\subsubsection{Procedure - Minimal group study (study 1)}

209 Data collection took place from 2014 to 2015 . Before the test day subjects were given

210 instructions and were handed out five $2 \mathrm{ml}$ polypropylene Eppendorf tubes for the saliva

211 samples, which they had to collect themselves at home the morning of the test day. They had to

212 start with the first sample directly after waking up and then had to collect another four samples

213 with 30 minutes in between. During the sampling period of 2 hours subjects were told to refrain

214 from eating, smoking and drinking anything but water. Directly after the first sample tooth

215 brushing was allowed, however it had to be finished at least 15 minutes before the second

216 sample, to prevent contamination by micro-bleeding.

217 Upon arrival at the test facility, the test procedure started with the group assignment, which was

218 a pencil and paper maze task. This task was intended to create an artificial group formation that

219 was unrelated to the experiment itself. Such a minimal group paradigm (MGP) has previously

220 been shown to evoke ingroup favoritism and intergroup bias (Tajfel et al. 1971). Subjects went

221 through the maze. After seven seconds time was stopped. Participants were instructed that,

222 according to the distance they covered in the maze, they were assigned to one of the two groups.

223 The two groups were named after two famous cartoon characters, which were used as the group

224 icons in the following experiments. To make this group assignment even more authentic to the 
225 subjects, maze templates that showed the cut-off distance dividing the two groups were shown to

226 the subjects. In reality, the group assignment was pre-determined by the experimenters to ensure

227 an equal distribution among the two groups. For subjects who were supposed to be in the 'fast

228 group' another template was used than for subjects who were assigned to the 'slow group'. After

229 the group assignment, subjects were given written instructions that explained the rules of the UG

230 (see Diekhof, Wittmer, and Reimers 2014; Reimers, Büchel, and Diekhof 2017 for comparison).

231 The UG was designed as a computer-based experiment that was run using the Presentation

232 software by NBS (Neurobehavioral Systems). A short training version was completed and all

233 further questions were answered. Subsequently, the UG was played in the role of the responder

234 (see below), followed by two questions asking about hypothetical offers in the role of the

235 proposer. After that subjects completed the Barratt-Impulsiveness-Scale (BIS; Patton et al.,

236 1995) and answered several questions from the German socio-economic panel that measure trust,

237 positive and negative reciprocity (Dohmen et al. 2008). Saliva samples were frozen at $-20^{\circ} \mathrm{C}$

238 until further analysis.

239

$240 \quad$ 2.1.3 Ultimatum Game in a minimal group context (study 1)

241 One famous and often applied economic decision task is the UG (Güth, Schmittberger, and

242 Schwarze 1982). In the UG two players, the proposer and the responder, interact in an economic

243 exchange. The proposer has to make an offer about how to split a fixed sum of money (or

244 experimental points) to the responder. If the responder accepts the offer, both players get paid

245 according to the proposed share. But in case he rejects the offer, both players get nothing.

246 Despite the costs, humans tend to offer almost equal shares and tend to reject unfair offers lower

247 than 20\% (Güth, Schmittberger, and Schwarze 1982; Henrich et al. 2005).

Peer] reviewing PDF | (2019:02:35282:2:0:NEW 19 Jul 2019) 
248 Here we applied a computer-based intergroup version of the UG (intergroup-UG) that was

249 similar to previously applied intergroup-UGs (Diekhof, Wittmer, and Reimers 2014; Reimers,

250 Büchel, and Diekhof 2017). The participants of the present study thereby acted in the role of the

251 responder and could accept or reject any offers made to them. Yet in contrast to these previous

252 studies, we will focus the analysis on the first session of the intergroup-UG here. In the first

253 session of the intergroup-UG, subjects play for their personal reward and do not receive any

254 further instructions regarding a competition between groups for an extra group bonus, which

255 would be the case in the second session of the intergroup-UG. In our previous studies (see for

256 example in Diekhof, Wittmer, and Reimers 2014), the first session was termed the "neutral

257 context", since there the group affiliation is not explicitly addressed as being important for the

258 accomplishment of the task goal, i.e., one's individual reward. In contrast, the second session

259 was referred to as the "competitive context", since there we also introduced the second task goal,

260 which was to achieve an additional bonus in form of a group reward for behavior that maximizes

261 the outcome of the group. In that way, the "neutral context" of the first session of the intergroup-

262 UG should reveal the latent parochial tendency of the person which is not enforced by an explicit

263 instruction that refers to the group identity of the proposers (see also Reimers, Büchel, and

264 Diekhof 2017). Moreover, the interpretation of the results from the competitive, second session

265 of the intergroup-UG is problematic. This is because the "neutral context" of session 1 always

266 precedes the "competitive context" of session 2. Consequently, transfer effects cannot be ruled

267 out from the naïve context of session 1 to the competition in session 2. For example, some

268 subjects might, after short reflection, regret that they rejected any offer during session 1 and

269 could switch to a more selfish-strategy, especially if they consider the group reward rather

270 unlikely to achieve. This could be particularly the case in a study in which ingroup cohesion 
271 might be expected to be rather lax (as in study 1) or in which more than two groups are

272 competing for the same group reward (like in study 2 below). In particular, when comparing the

273 results from different studies for consistency this could increase the risk of a study-specific bias

274 in the "competitive context" of session 2 that might obscure or contaminate the already subtle

275 effect of testosterone on behavior.

276 In study 1, the first session consisted of 40 single-shot interactions, during which subjects faced 277 either an ingroup or an outgroup proposer (i.e., 20 trials each). The proposers were always 278 endowed with 10 points and half of their offers were either fair (i.e., 4 or 5 out of 10 points) or 279 unfair (i.e., 1, 2, or 3 out of 10 points). Offer types and group membership of the proposers were 280 pseudorandomized and counterbalanced for condition transitions. Fair offers contained either 4 281 points ( 2 trials/group) or 5 points ( 8 trials/group) out of 10 points, while unfair offers were 282 determined as 1 point ( 4 trials/group), 2 points ( 4 trials/group) or 3 points ( 2 trials/group). This 283 means that $80 \%$ of unfair proposals offered $20 \%$ or less of the initial endowment in the present 284 study. Since $20 \%$ is assumed to be the threshold at which subjects start to reject more and more 285 unfair offers (Güth, Schmittberger, and Schwarze 1982; Henrich et al. 2005), a rejection rate 286 equal to or exceeding $80 \%$ of all unfair offers, i.e., comprising those from both the in- and 287 outgroup in our version of the intergroup-UG, was assumed to reflect a high degree of inequity 288 aversion.

289 In the intergroup-UG the proposers were introduced with a photo and their first name including 290 initials of the surname to increase authenticity. The photographs showed a frontal view of the 291 face with a neutral expression. The pictures were taken from other male students of Hamburg 292 University about five years before the present study. To control for familiarity, we asked all 293 participants after the experiment whether they knew anyone, but this was not the case. The group 
294 membership was indicated by small group icons (i.e., the cartoon characters). To further

295 emphasize the social nature of the task, subjects were told that the proposers were former

296 participants and that participants of the present study would now decide about their payoff.

297 However, all proposers and their offers were pre-determined by the experimenter.

298 Before starting the intergroup-UG, participants were instructed to decide about each offer

299 according to their individual preference. As they were told in the instructions, each decision

300 determined their additional payment and the accumulated points would be translated into Euros.

301 A total of 2.50 Euros was the maximum reward that could be accumulated in the first session.

302 Subjects also performed the intergroup-UG in a "competitive context" (session 2) for the same

303 reward and the additional chance to win a group bonus (see Diekhof et al., 2014 for comparison).

304 The data from the second session were however not analyzed here, for reasons outlined above.

305 After having completed the intergroup-UG (total duration of 30 minutes), subjects were asked to

306 switch to the role of the proposer and to make two offers to an anonymous ingroup and outgroup 307 member.

308

309 2.1.4 Analysis of hormonal parameters from human saliva (study 1)

310 After having collected and frozen all samples, the saliva samples were thawed at $26^{\circ} \mathrm{C}$ and then

311 vortexed and centrifuged at RCF $604 \times \mathrm{g}$ in a common Eppendorf Minispin centrifuge for 5

312 minutes to discard mucus and other residuals. The five morning samples were pooled into one

313 aliquot by extracting an equal volume of each sample and mixing them together. This was done

314 to control for the pulsatile secretion pattern of testosterone and ensured that the morning peak

315 concentration was captured by the pooled aliquot sample. Samples that looked contaminated

316 (e.g., had no transparent color or contained traces of blood) were discarded. Testosterone 
317 concentrations in the aliquot samples were analyzed using two enzyme-linked immunosorbent

318

321

322

323

324 325

326

327 328 335

336 337

assay (ELISA) kits by Demeditec Diagnostics (sensitivity $=2.2 \mathrm{pg} / \mathrm{ml}$ ). The denoted intra-assay coefficient of variation is indicated as $6.58 \%$ at $90.8 \mathrm{pg} / \mathrm{ml}$ and the interassay variation is given as $7.4 \%$ at $74.3 \mathrm{pg} / \mathrm{ml}$. All aliquots were assayed twice and two control samples, one with a low and another one with a high concentration, were included.

\subsubsection{Statistical analyses of study 1}

Mean rejection rates in all experimental conditions, i.e., group membership of proposer (ingroup, outgroup), and type of offer (fair, unfair), were calculated for each subject. The testosterone concentration was standardized (z-transformed). The rejection rates were then submitted to a repeated-measures ANOVA, to test whether they were affected by group membership, offer type and standardized testosterone level.

In case of a significant Mauchly-test for sphericity in the ANOVA, results were reported using the Greenhouse-Geisser-corrected values. Post-hoc assessment of the interactions with standardized testosterone were further subjected to simple slope analyses based on the estimated marginal means. We thereby compared the interaction effect in men with high testosterone (standardized testosterone at $+1 \mathrm{SD}$ ) and those with low testosterone (standardized testosterone at -1SD) using t-tests. P-values smaller than 0.05, two-tailed, were considered as significant.

\subsection{Study 2}

\subsubsection{Participants of study 2}

34 healthy male students (mean age \pm SD: $25.06 \pm 4.46$ years) participated in the second study. The subjects were recruited via online advertisement on a campus website and by word of 
340 mouth. Participants reported no drug or alcohol abuse, and were free of any chronic illness

341 including disorders of the hormone system as well as psychiatric or neurological disorders. They

342 were also free of medication. A participation fee and an additional monetary reward related to

343 the points acquired during the intergroup-UG were paid (see Study 1). All subjects gave written

344 informed consent and the study was approved by the local ethics committee (Aerztekammer

345 Hamburg).

346

\section{$347 \quad$ 2.2.2 Procedure of political supporter study (study 2)}

348 Key to participation in study 2 was an interest in politics, which was assessed by the German

349 Scale for Political Interest (the PIKS questionnaire; (Otto and Bacherle 2011)). The PIKS

350 questionnaire was sent by e-mail to the potential participant. The five questions on political

351 interest and involvement were to be answered on a 5-point-Likert-scale, possible options ranging

352 from 5, “applies fully”, to 1, “doesn’t apply at all”, resulting in a mean PIKS-score $( \pm$ SD) of

$3534.14( \pm 0.59)$ for all participants. To determine group affiliation, the participants were

354 additionally asked to rank the 6 political parties, which had a chance to win seats in the German

355 parliament (Bundestag) according to their preference in the upcoming vote. The rating was

356 thereby to be based on the shared values a participant held with the parties. The political parties

357 comprised the four mainstream parties, i.e., the SPD (Social Democrats), the CDU (Christian

358 Democrats), the Greens, and the FDP (Free Liberals), as well as two parties from the extreme

359 left and right wing, i.e., The Left and the AfD (Alternative for Germany), which all succeeded to

360 acquire seats in the German Bundestag in 2017. The rating procedure was carried out with

361 attention to privacy of the participant in order to avoid social pressure and to rule out bias from

362 the experimenter's side. Based on the political ranking, the participants were ascribed an 
363 affiliated ingroup (ranked as 1), while all other parties were considered as outgroups with

364 varying degree of social distance depending on their rank. The party with a ranking of 6 was

365 considered as the most distant outgroup. For subsequent trend analysis, these individual ranks

366 were used. In order to compare the results of study 2 to those of study 1, we averaged the data

367 (UG rejection rates) from ranks 1 to 3 as well as the data from ranks 4 and 6 . By this we created

368 one relatively close 'ingroup' (ranks 1 to 3 ) that shared similar political values from one end of

369 the political spectrum (e.g., the left, more liberal wing) with the respondent, while the 'outgroup'

370 (ranks 4 to 6) consisted of more distant parties from the other end of the political spectrum (e.g.,

371 the more conservative parties oriented towards the right wing or vice versa). Otherwise the

372 procedure of study 2 closely matched the one employed in study 1, including the same

373 questionnaires and saliva sampling procedure. Data collection took place in 2017. The complete

374 experiment lasted about 1 hour and 15 minutes in total, which included the two sessions of the

375 UG (see above) followed by a short distraction period and a face memory task.

376

$377 \quad$ 2.2.3 Ultimatum game in a political context (study 2)

378 The structure of the intergroup-UG strongly resembled the one of the minimal group study

379 (approximate total duration of 30 minutes), starting with participants in the role of the responder

380 and finally switching to the role of the proposer. Yet, in contrast to study 1, proposals came from

3816 different groups that comprised the supporters from the 6 political parties. Again, each

382 proposer was indicated by a unique photograph. The photographs were taken from the

383 anonymous experimental picture stock of the department as well as from other universities. The

384 pictures to be used in the game had previously been tested for approachability, making sure that

385 none of the faces evoked a biased response in the participants. The approachability test was 
386

387

388

389

390

391

392

393

394

395

396

397

398

399

400

401

402

403

404

405

406

407

408

performed in an independent sample of 30 students, male and female, who rated each of the faces on a seven-point Likert-scale answering the question: "Would you ask this stranger for directions?" Based on the rating, three faces remained unused in the experiment due to an extraordinary mean approachability rating, the others were equally distributed into the categories of (un)fairness and political inclination by approachability.

The first, unbiased session of the intergroup-UG comprised 48 single-shot computer game interactions with an apparently real, but actually fictional opponent indicated by the unique photograph. In an introductory text, participants were falsely informed about a nation-wide study in which other students had already participated, whose pictures, proposals and party affiliation participants were about to see in the game. From each political party four offers were considered as (rather) fair (with two proposers offering either 4 or 5 points of 10), while the remaining four offers were unfair and included one offer of 1 point and 2 points, each, as well as 2 offers of 3 points. This resulted in a different threshold for determination of the individual decision strategy in study 2. Here, only $50 \%$ of the unfair proposals offered $20 \%$ or less of the initial endowment. This is why a mean rejection rate equal to or exceeding $50 \%$ across all unfair offers of the 6 ranks was assumed to reflect a high degree of inequity aversion.

\subsubsection{Cued recall task (memory for faces) of study 2}

In the second study we also wanted to test (1.) whether the different strategy groups differed in their overall ability to recollect the identity of faces from previous interactions, in particular unfair ingroup members, (2.) whether they showed a differential recollection for persons who treated them unfair or fair on previous trials, and (3.) whether recollection ability varied in relation to testosterone level. Similar procedures have already been employed in studies using 
409 related paradigms like the dictator game and demonstrated a memory advantage during

410 recollection of the identity of unfair interaction partners, particularly for those from the ingroup

411 (Hechler, Neyer, and Kessler 2016). The face memory task followed a short distraction period, in

412 which participants filled out several questionnaires including the Trust and Reciprocity

413 questionnaire (Dohmen et al. 2008) and a demographic questionnaire. In addition, they were

414 asked to see themselves as proposer in an UG and make their own proposals to future opponents.

415 These proposals were to be made to 6 hypothetical future respondents, portrayed as grey

416 anonymous silhouettes, each of whom was stated to be favoring one of the aforementioned 6

417 political parties. Offers were allowed to range between 1 and 5 points. Another assignment

418 consisted of the same proposal task with a variation: instead of the UG, the participants were

419 playing a dictator game, in which none of the anonymous partners would be able to reject their

420 offer.

421 The subsequent cued recall task was presented to the participants by surprise. The 48 faces used

422 in the two sessions of the UG were pseudorandomized and mixed with 48 new faces which had

423 been selected from the same database and tested for approachability as stated above. Appearing

424 one after another like in the UG, none of the faces were juxtaposed with any information.

425 Instead, participants were asked to indicate with a button press whether the face was known or

426 unbeknownst to them (old vs. new decision). Each trial ended with the subject's decision. The

427 aim of this face memory task was to assess individual memory for unfair opponents in

428 relationship with the ingroup-outgroup dynamic (Hechler, Neyer, and Kessler 2016).

429

\section{$430 \quad$ 2.2.5 Hormone analysis (study 2)}

431 The analysis of saliva samples followed the procedure described above (see study 1 above). 


\subsubsection{Statistical analyses (study 2)}

434 Data analysis of the UG data in study 2 paralleled the analysis in study 1 . We performed a 435 repeated measures ANOVA to assess the influence of group affiliation, offer type and 436 standardized testosterone on rejection rates. Post-hoc testing also followed the procedure in study 437 1. In order to also assess the 6 ranks in more detail, we further performed a linear trend analysis 438 to determine the influence of social distance (political party ranking from 1 to 6 ) on rejection 439 rates, as outlined in detail in the results section. In contrast to study 1, study 2 also incorporated 440 a cued recall task, in which we wanted to examine differences in the ability to recollect

441 previously encountered face identities as a function of their unfairness and social distance as well 442 as in relation to testosterone and the two strategy groups. For this purpose we analyzed the hit 443 rates for recalling the unfair proposers from the 'ingroup' (ranks 1 to 3) and the outgroup (ranks 4444 to 6$)$.

\section{Results}

447

448

\subsection{Results of Study 1}

449 Replicating previous results (Diekhof, Wittmer, and Reimers 2014; Reimers, Büchel, and 450 Diekhof 2017; Reimers and Diekhof 2015) a clear tendency towards parochialism was found. A 4512 ("group": ingroup, outgroup) x 2 ("offer": unfair, fair) repeated-measures ANOVA with the 452 covariate "standardized testosterone" revealed a significant two-way interaction between 453 "group" and "offer" $\left(\mathrm{F}_{1,59}=5.44 ; \mathrm{p}=0.023\right.$; partial eta $\left.{ }^{2}=0.08\right)$. In addition, we also found a 454 main effect of "group" $\left(\mathrm{F}_{1,59}=10.56 ; \mathrm{p}=0.002\right.$; partial eta $\left.{ }^{2}=0.15\right)$ as well as of "offer" $\left(\mathrm{F}_{1,59}=\right.$ 455 194.07; $\mathrm{p}<0.001$; partial eta $\left.{ }^{2}=0.77\right)$ (see also Table 1). Apart from that, there was a significant 
456 three-way interaction between "offer", "group" and "standardized testosterone" $\left(\mathrm{F}_{1,59}=7.82 ; \mathrm{p}=\right.$ 457 0.007; partial eta ${ }^{2}=0.12$ ). Post-hoc simple slope analysis of the estimated marginal means 458 indicated that unfair offers were more likely to be rejected if they came from an outgroup 459 proposer than from an ingroup member, however only if the respondents were men with 460 relatively high testosterone levels $\left(\mathrm{t}_{(59)}=3.64, \mathrm{p}=0.001\right)$. For men with low testosterone the 461 same comparison was not significant $\left(\mathrm{t}_{(59)}=0.93, \mathrm{p}=0.358\right)$ (Bonferroni-corrected threshold: $\mathrm{p}=$ 462 0.025). In case of rather fair offers, which also include the $40 \%$ offers, both participants with low 463 and high testosterone level tended to be more likely to reject offers from outgroup than from 464 ingroup members, yet these differences were only numerical as they missed the threshold for significance in a two-tailed t-test (high testosterone: $\mathrm{t}_{(59)}=1.81, \mathrm{p}=0.076$; low testosterone: $\mathrm{t}_{(59)}=$ $1.96, \mathrm{p}=0.055)($ Bonferroni-corrected threshold: $\mathrm{p}=0.025)$. The results from the simple slope analysis of the estimated marginal means were confirmed by an analysis based on the complete data that compared the subjects with a testosterone concentration above the standardized mean (0) as the high $\mathrm{T}$ group $(\mathrm{n}=29)$ with those with a testosterone level below 0, i.e., the low $\mathrm{T}$ group $(\mathrm{n}=32)$. Accordingly, only the high T group showed increased rejections of the unfair 471 outgroup offers compared to unfair ingroup offers $\left(\mathrm{t}_{(28)}=2.97, \mathrm{p}=0.006\right)$, while this was not the 472 case in the low $\mathrm{T}$ group $\left(\mathrm{t}_{(31)}=1.40, \mathrm{p}=0.173\right)$. Again both groups showed enhanced rejection 473 rates when rather fair offers were made by an outgroup member, whereby only in the low $\mathrm{T}$ 474 group this difference was significant (high $\mathrm{T}$ group: $\mathrm{t}_{(28)}=1.84, \mathrm{p}=0.077$; low $\mathrm{T}$ group: $\mathrm{t}_{(31)}=$ $4752.13, \mathrm{p}=0.041)($ see Fig. 1A). Yet, the latter effect did not survive the Bonferroni correction $(\mathrm{p}<$ 476 0.025), which needed to be applied since the same data were also used in the direct comparisons 477 of rejection rates between the testosterone groups that yielded no significant differences. We 478 only found a non-significant increase in the Delta of rejections of unfair offers made by the 
479 outgroup minus those from the ingroup $\left(\operatorname{Delta}_{(\mathrm{high} \mathrm{T})}\right.$ : mean $=17.93 \%$; sem $=6.05 \%$; Delta (low T) $_{\text {: }}$ :

480 mean $=5.31 \% ;$ sem $\left.=3.81 \% ; \mathrm{t}_{(59)}=1.77, \mathrm{p}=0.084\right)$. Collectively, these results indicate a

481 somewhat greater parochialistic tendency in men at the high end of the testosterone distribution,

482 who differentiated more between unfair proposals from the out- and the ingroup.

483 In a second step, we also looked at the proposals made by the participants to anonymous ingroup

484 and outgroup members after having completed the UG. A repeated measures ANOVA with the

485 factor "group" and the covariate standardized testosterone only showed a significant main effect

486 of "group" $\left(F_{1,59}=19.48 ; p<0.001\right.$; partial eta $\left.{ }^{2}=0.25\right)$, while no significant interaction with nor

487 a main effect of standardized testosterone could be observed. A post hoc t-test showed that

488 participants offered significantly more points to an anonymous ingroup member (mean \pm sem $=$

$4894.1 \pm 0.1$ points $)$ compared to an outgroup member (mean \pm sem $=3.4 \pm 0.2$ points $)\left(t_{(60)}=4.45\right.$,

$490 \mathrm{p}<0.001)$, yet this effect was independent of testosterone.

491 Finally, being in the 'fast' or 'slow group' did not influence the rejection rates, which was tested

492 by re-running the first ANOVA including the subject's artificial group membership. Also when

493 comparing rejection rates of the 'fast' and 'slow group' directly, no significant differences

494 emerged $(\mathrm{p}>0.347)$.

495

$496 \quad 3.2$ Results of Study 2

497 Study 2 was intended to examine whether the results related to parochial altruism in study 1

498 could also be found in a more natural group context (supporters of political parties tested during

499 the German election year 2017). First of all, we found that the political preferences of our student

500 sample were clearly oriented towards the left wing parties (SPD, The Greens, The Left), which

501 was also reflected by the mean ranking across participants (lower mean ranks indicate a more 
502 favorable rating (mean \pm sem): $\mathrm{SPD}=2.44 \pm 0.23$, The Left $=2.94 \pm 0.29$, The Greens $=2.97 \pm$ $5030.23, \mathrm{CDU}=3.06 \pm 0.22, \mathrm{FDP}=4.03 \pm 0.23, \mathrm{AfD}=5.56 \pm 0.20)$. Moreover, in line with study 1

504 and our previous results (Diekhof, Wittmer, and Reimers 2014; Reimers, Büchel, and Diekhof

505 2017; Reimers and Diekhof 2015) we found a significant two-way interaction $\left(\mathrm{F}_{3.69,121.78}=2.81\right.$;

$506 \mathrm{p}=0.032$; partial eta $\left.^{2}=0.079\right)$ in the repeated-measures ANOVA with the factors rank of

507 "political preference" (6 ranks) and "offer" (unfair, fair). This was also reflected by a significant 508 linear trend with increasing social distance, as determined by an univariate ANOVA with the 509 independent factor "rank" and the dependent variable "mean rejection rate for unfair offers" $510\left(\mathrm{~F}_{1,203}=9.94 ; \mathrm{p}=0.002\right)$. When comparing rejection rates between the most extreme cases, i.e., 511 the first rank (one's favorite political party) and the last rank (the $6^{\text {th }}$ rank, which is associated 512 with the least liked party with the most distant political values in the ranking) we found 513 significantly enhanced rejection rates for offers by rank 6, both in the context of fair and unfair 514 offers $(p<0.001)$. In the comparison of the rank 1 with the other ranks, we also documented 515 another two significant differences in the treatment of unfair offers by supporters of distant 516 political parties ranked as 4 and 5, whose rejection was also more frequent $(p<0.001)$ (see Fig. 5172 , which displays the rejection rates related to unfair offers). All these differences survived a 518 Bonferroni corrected threshold for multiple comparisons of 0.01. This means, that the design of 519 study 2 was also suitable to show parochialistic tendencies amongst the supporters of political 520 parties. Also the subsequent subdivision of ranks into the "ingroup" (ranks 1 to 3 ) and the 521 "outgroup" (ranks 4 to 6) below is in line with these observations of a differential treatment of 522 ranks 4 to 6 , but not ranks 2 and 3 compared to rank 1.

523 More importantly, the main question was whether these parochialistic tendencies were also 524 related to endogenous testosterone as already documented in study 1 . For this purpose and to 
525 make the data of study 2 (6 groups) most comparable to those of study 1 ( 2 groups) the rejection

526 rates from ranks 1 to 3 were combined as the "ingroup", while the remaining ranks represented

527 the "outgroup". These data were then subjected to a repeated-measures ANOVA with the factors

528 "offer" and "group" and the covariate standardized testosterone. In contrast to study 1 this

529 ANOVA only revealed two main effects of "group" and "offer", while the three-way interaction

530 of the factors merely approached statistical trend level (see Table 2 for details). Nevertheless,

531 following the procedure of study 1 we subjected the estimated marginal means to an exploratory

532 simple slope analysis. This exploratory analysis showed that, similar to study one, only men with

533 very high testosterone showed a significantly increased rejection rate for unfair offers made by

534 outgroup compared to ingroup members $\left(\mathrm{t}_{(32)}=4.46, \mathrm{p}<0.001\right)$, while this was not the case in

535 men with low testosterone $\left(\mathrm{t}_{(32)}=1.78, \mathrm{p}=0.085\right)($ Bonferroni-corrected threshold: $\mathrm{p}<0.025)$.

536 Further, fair offers of the outgroup were more often rejected than fair ingroup offers by both

537 testosterone groups (high testosterone: $\mathrm{t}_{(32)}=2.68, \mathrm{p}=0.012$; low testosterone: $\mathrm{t}_{(32)}=2.50, \mathrm{p}=$

538 0.018) (Bonferroni-corrected threshold: $\mathrm{p}<0.025)$. If subdividing the sample by the standardized

539 mean of testosterone ( 0$)$ in a group with above $(n=16)$ and one below average testosterone

$540(\mathrm{n}=18)$ direct comparisons showed no differential rejection pattern as originally demonstrated in

541 study 1. Further paired t-tests comparing rejection rates for fair ingroup vs. outgroup offers and

542 unfair ingroup vs. outgroup offers in the two testosterone groups all yielded significant

543 differences, that were in line with the interaction effect between "group" and "offer" (all p <

544 0.020; Bonferroni-corrected threshold: $\mathrm{p}<0.025$; see Fig. 1B). This suggests that there was no

545 clear association between testosterone and parochialism in this smaller sample of political

546 supporters. 
547 Similar to study 1, the ANOVA of the proposals the participants made to anonymous members

548 of the first and the last rank after completion of the UG yielded no interaction with standardized

549 testosterone, yet only revealed a main effect of "group" $\left(F_{1,32}=26.40 ; p<0.001\right.$; partial eta $^{2}=$

550 0.45). A post hoc t-test showed that participants offered significantly more points to a member of

551 the closest rank 1 (mean \pm sem $=4.6 \pm 0.1$ points) compared to a member of most distant rank 6

$552($ mean \pm sem $=3.0 \pm 0.3$ points $)\left(\mathrm{t}_{(33)}=5.17, \mathrm{p}<0.001\right)$.

553 Finally, in study 2 subjects performed a surprise cued recall task that was similar to the one used

554 by Hechler, Neyer, and Kessler (2016). However, in our task version the group identity of the

555 faces shown was not indicated during the memory test, but all faces were shown without any

556 notion of group identity. It has been suggested that there may be a memory advantage for

557 individuals of one's own group, especially if they exhibited schema-incongruent behavior (e.g.,

558 behaved unfairly) (Hechler, Neyer, and Kessler 2016). We performed a repeated-measures

559 ANOVA with the factors "offer" and "group" and the covariate standardized testosterone to

560 assess their effects on memory performance. This yielded a significant two-way interaction

561 between "offer" and testosterone $\left(F_{1,32}=5.57 ; p=0.025\right.$; partial eta $\left.{ }^{2}=0.15\right)$, but no other

562 significant effect emerged (Table 3). The simple slope analysis of the estimated marginal means

563 revealed one significant difference that was restricted to subjects with low testosterone. These

564 participants showed a better recall rate for fair than unfair proposers $\left(t_{(32)}=2.53, p=0.017\right)$, yet

565 independent of group (Bonferroni-corrected threshold: $\mathrm{p}<0.025$ ). In the analysis of all subjects

566 with a testosterone level below the standardized mean $(n=18)$ an increased hit rate for the

567 identity of fair proposers per se (mean \pm sem $=51.3 \% \pm 3.8 \%$ correct $)$ compared to unfair

568 proposers could also be observed (mean $\pm \mathrm{sem}=44.0 \% \pm 4.6 \%$ points), yet this numerical

569 difference was not significant $\left(\mathrm{t}_{(17)}=1.47, \mathrm{p}=0.11\right)$. Similarly, the numerically difference in 
570 recall of unfair proposers between men with high testosterone $(n=16 ;$ mean \pm sem $=52.6 \% \pm$

$5713.6 \%$ correct $)$ and those with low testosterone $(n=18 ;$ mean \pm sem $=44.0 \% \pm 4.6 \%$ points $)$ did

572 not reach significance $\left(\mathrm{t}_{(32)}=1.450, \mathrm{p}=0.157\right)$. It thus remains to be determined in a bigger

573 sample whether testosterone may promote memory for unfairness and whether better memory

574 performance indeed depends on group affiliation as previously suggested.

575

$576 \quad 3.3$ Analysis of the combined data from study 1 and 2

577 The previous results suggested similar effects of testosterone on parochialistic behavior in the

578 two studies. However, the observations made in study 2 were not significant, which was most

579 likely a result of the smaller sample size. We therefore combined the ingroup and outgroup data

580 from the UG in a meta-analysis of all cases $(n=95)$ and re-ran the repeated-measures ANOVA

581 of the rejection rates described previously, this time with the additional between-subjects factor

582 "study". This analysis confirmed the significant three-way interaction of "offer", "group" and

583 standardized testosterone $\left(\mathrm{F}_{1,92}=10.65 ; \mathrm{p}=0.002\right.$; partial eta $\left.{ }^{2}=0.10\right)$ as well as the two main

584 effects of the factors "offer" $\left(F_{1,92}=222.29 ; \mathrm{p}<0.001\right.$; partial eta $\left.{ }^{2}=0.71\right)$ and "group" $\left(\mathrm{F}_{1,92}=\right.$

585 29.46; $\mathrm{p}<0.001 ;$ partial eta ${ }^{2}=0.24$ ) (see also Table 4). Further, the simple slope analysis of the

586 estimated marginal means showed that unfair offers were more often rejected if they came from

587 an outgroup proposer than from an ingroup member, however only if the respondents were men

588 with high testosterone $\left(\mathrm{t}_{(93)}=5.28, \mathrm{p}<0.001\right)$. For men with low testosterone the same

589 comparison yielded no significant difference $\left(t_{(93)}=1.71, p=0.091\right)$. In case of the rather fair

590 offers, all participants rejected offers from outgroup members more often than those from

591 ingroup members (high testosterone: $\mathrm{t}_{(93)}=3.61, \mathrm{p}=0.001$; low testosterone: $\mathrm{t}_{(93)}=3.58, \mathrm{p}=$

592 0.001). Apart from these replications, we also found a two-way interaction between "offer" and 
593 "study" $\left(\mathrm{F}_{1,92}=8.00, \mathrm{p}=0.006\right.$; partial eta $\left.{ }^{2}=0.08\right)$. Post-hoc comparisons showed that the

594 participants of study 1 rejected unfair offers more often (mean \pm sem $=68.6 \% \pm 4.2 \%$ ) than the

595 participants of study $2($ mean \pm sem $=53.4 \% \pm 5.5 \%)\left(\mathrm{t}_{(93)}=2.2, \mathrm{p}=0.03\right)$ indicating a higher

596 degree of inequity aversion in the first sample. We therefore also looked into the questionnaire

597 data from the two studies as these might help to explain these differences in inequity aversion

598 (please note that missing questionnaire data of some subjects explain the reduced degrees of

599 freedom below). We found that the participants of study 1 were significantly more impulsive as

600 indicated by a higher BIS score $\left(\right.$ BIS $_{\text {study } 1}:$ mean \pm sem $\left.=65.7 \pm 1.3\right)$ compared to the subjects of

601 study $2\left(\right.$ BIS $_{\text {study } 2}:$ mean \pm sem $\left.=60.4 \pm 1.4\right)\left(\mathrm{t}_{(88)}=2.60, \mathrm{p}=0.011\right)$. The participants of study 1

602 also showed a significantly enhanced negative reciprocity score in the trust and reciprocity

603 questionnaire (negative reciprocity study $1_{1}$ : mean $\pm \mathrm{sem}=8.65 \pm 0.25$; negative reciprocity study $2_{2}$ :

604 mean $\left.\pm \mathrm{sem}=5.52 \pm 0.29 ; \mathrm{t}_{(91)}=7.94, \mathrm{p}<0.001\right)$. At the same time both the trust and the positive 605 reciprocity score were significantly reduced in study 1 (trust study $1_{1}$ : mean \pm sem $=7.20 \pm 0.21$;

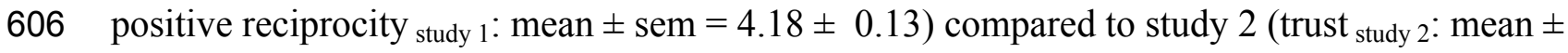
607 sem $=8.48 \pm 0.27$; positive reciprocity study $2_{2}:$ mean $\left.\pm \mathrm{sem}=10.58 \pm 0.24\right)\left(\right.$ trust $_{\text {comparison }}: \mathrm{t}_{(91)}=$ $6083.65, \mathrm{p}<0.001$; positive reciprocity comparison: $\left.\mathrm{t}_{(91)}=23.57, \mathrm{p}<0.001\right)$. These results suggest that the 609 participants from the two studies might have shown a general difference in the way to treat other 610 humans in economic interactions, which might explain the increased rejection rate in relation to 611 unfair offers made in study 1. Interestingly, when correlating of the scores from the trust and 612 reciprocity questionnaire with the degree of political interest in subjects of study 2 (PIKS score), 613 we found a negative relationship between negative reciprocity and PIKS score $(r=-0.396 ; p=$ 614 0.021). Unfortunately, the $\mathrm{p}$-value did not survive the Bonferroni-correcte threshold of $\mathrm{p}=$ 6150.0167 (the PIKS score was used in three correlations with the trust, negative and positive 
616 reciprocity scores). So we can only speculate that people with a higher political interest, who

617 also show a stronger need to get political information to make an informed voting decision,

618 might be more conscientious, which is why they would show less retaliation, yet more positive

619 reciprocity and trust .

620 In addition to that, we wanted to further ascertain to what extent the actual degree to which an

621 individual shows a 'parochialism bias', i.e., the differential treatment of unfair offers made by

622 the ingroup and the outgroup, may be related to testosterone. For this, we performed a correlation

623 analysis with the data of all cases $(n=95)$. This analysis revealed a small, yet significant positive

624 correlation between standardized testosterone and the delta of the rejection rate of unfair

625 outgroup minus unfair ingroup offers (Delta $\mathrm{out}_{\text {-in }}: \mathrm{r}=0.245, \mathrm{p}=0.017$; see Fig. 3 ).

626 Finally, in order to further explore this positive correlation we followed the procedure of our

627 previous study (Reimers, Büchel and Diekhof, 2017), in which we subdivided the sample by the

628 individual tendency to treat highly unfair proposals. It has previously been assumed that offers of

$62920 \%$ of the original share are assumed to be the threshold at which rejection rates start to

630 increase tremendously, yet at the same time inter-individual variation of rejection rates increases

631 (Güth, Schmittberger, and Schwarze 1982; Henrich et al. 2005). In the first study 80\% of unfair

632 proposals offered $20 \%$ or less of the initial endowment, while in study $250 \%$ of the unfair

633 proposals fell within this range. Thus a rejection rate for unfair offers (regardless of group) that

634 was exceeding these study-specific thresholds of $80 \%$ (study 1 ) and 50\% (study 2) was assumed

635 to reflect a high degree of inequity aversion that was marked as the first individual decision

636 strategy (inequity averse subjects). In contrast, rejection rates well below the respective study-

637 specific threshold were considered as reflecting both a high tolerance for unfairness and the

638 motivation to collect as many points as possible for oneself (selfish strategy). Based on this 
639 classification, that was exclusively based on the experimental structure of the UG task (i.e.,

640 referred to the percentage of highly unfair trials as cut-off value), participants were divided into

641 the two strategy groups (see also Reimers, Büchel and Diekhof, 2017 for a similar procedure).

642 This sub-division showed that the positive correlation between standardized testosterone and the

643 parochialism bias, i.e., delta of the rejection rate of unfair outgroup minus unfair ingroup offers,

644 stemmed from the selfish subjects $(n=44 ; r=0.394, p=0.008)$ with their relatively few

645 rejections overall (selfish group: mean rejection rate $_{\text {unfair }} \pm \mathrm{sem}=34.3 \% \pm 3.6 \%$ ), while it was

646 not present in the more inequity averse subjects $(n=51 ; r=-0.016, p=0.909)$. One might argue

647 that the absence of a correlation could be explained by the generally high rejection rates in the

648 latter group (mean rejection rate $\mathrm{unfair}_{\mathrm{i}} \pm \mathrm{sem}=88.1 \% \pm 1.9 \%$ ) and the resulting ceiling effect.

649 However, it may also be that, similar to Reimers, Büchel and Diekhof (2017), selfish and 650 inequity averse subjects were differently affected by testosterone when deciding how to treat 651 unfair offers made by different groups.

652

653

654 4. Discussion

655 The aim of this research was to test whether an artificial group formation (study 1) and a natural 656 group affiliation (study 2) would both install a sufficient group commitment to measure 657 individual differences in parochial altruism in the intergroup-UG and to investigate how these 658 differences may be related to circulating testosterone. In study 1, the subjects were divided into 659 two artificial groups according to the distance they had covered in a maze task after seven 660 seconds. For study 2, we tested supporters of political parties in the German election year of 661 2017, who showed a strong interest in politics and had a clear favorite party as well as 662 reservations of varying degree towards the other parties competing in the election. The subjects 
663 of both studies acted as responders in a computer-based intergroup-UG with single-shot

664 interactions and offers of varying degrees of unfairness. In the end, participants switched to the

665 role of the proposer and had to decide about hypothetical offers they made to members of their

666 own group or the other group(s). Moreover, study 2 also included a cued recall task to assess

667 memory for previously unfair proposers of the different groups. Altogether, both studies showed

668 a relationship between testosterone and the intergroup bias, thus supporting the assumption that

669 endogenous testosterone may be related to male parochial altruism. However, the correlative

670 nature of the two studies and the relatively small sample sizes limit any strong inferences and

671 render the present results rather preliminary.

672

673 4.1 Parochial altruism in the intergroup UG emerged across different studies

674 As hypothesized and in line with previous studies (Diekhof, Wittmer, and Reimers 2014;

675 Reimers, Büchel, and Diekhof 2017) a marked pattern of parochial altruism with higher rejection

676 rates in outgroup than ingroup interactions was evident in both studies, which was also reflected

677 by a linear trend for increased social discounting with increasing social distance in study 2

678 corresponding to the results of earlier studies (e.g., Strombach et al. 2015). Such rejections could

679 indicate the willingness to forgo points in order to punish outgroup members, which would

680 reflect a behavior consistent with the theory of parochial altruism (Choi \& Bowles, 2007). An

681 alternative view would interpret this behavior as spiteful rather than altruistic, with the major aim

682 to minimize the other's payoff in order to equalize relative gain between the interaction partners

683 (Jensen 2010). It has been assumed that spiteful individuals see others as competitors, whose

684 gains negatively affect their own utility (Espín et al. 2015). Yet, it is not clear why spitefulness

685 should necessarily follow a parochial pattern or should lead to increased punishment of one 
686 social group above the other. We observed that 41 of the 95 participants $\left(\mathrm{n}_{\text {study } 1}=20, \mathrm{n}_{\text {study } 2}=21\right)$

687 showed a preference to minimize the payoff of unfair outgroup members more than that of unfair

688 ingroup members (Mean Delta ${ }_{\text {out-in }}$ for unfair offers \pm sem $=32.19 \% \pm 4.19 \%$ ). This behavior

689 would fit with the theory of parochial altruism (Choi and Bowles, 2007). First, these rejections

690 indirectly benefited the relative gain of the ingroup, as did the somewhat lowered fairness norm

691 in ingroup interactions. Second, it also clearly harmed the payoff of the outgroup, yet this

692 happened at the responder's expense, since in the latter case the responder declined a share he

693 could have otherwise acquired for himself. In contrast, another 14 subjects $\left(\mathrm{n}_{\text {study } 1}=11, \mathrm{n}_{\text {study } 2}=\right.$

694 3) preferentially rejected unfair ingroup offers compared to unfair outgroup offers (Mean

695 Delta $_{\text {out-in }}$ for unfair offers \pm sem $=-10.87 \% \pm 1.09 \%$ ). This decision behavior would rather fit

696 with the theory of indirect reciprocity (Gintis et al., 2003; Yamagushi \& Mifune, 2008),

697 according to which rejections of unfair offers by ingroup members even in single-shot

698 interactions promote the adherence to fairness norms and cooperation within one's group.

699 Altruistic punishment of ingroup unfairness is thereby assumed to be the glue of large

700 anonymous societies that follow the principle of generalized exchange. In addition, harsher

701 punishment of norm violations in the ingroup may not only increase the individual probability to

702 get fairer shares in the future, but could benefit one's social reputation and thus enhance

703 individual social status (Fehr and Gächter 2002; Yamagishi et al., 2012). Finally, the remaining

70440 subjects $\left(\mathrm{n}_{\text {study } 1}=30, \mathrm{n}_{\text {study } 2}=10\right)$ showed no difference in responding to unfair offers from the

705 out- and the ingroup. This latter group also showed significantly higher rejection rates in

706 response to unfair offers per se (mean \pm sem $=73.01 \% \pm 5.88 \%)$ than the subjects with a

707 negative Delta ${ }_{\text {out-in }}($ mean \pm sem $=53.37 \% \pm 4.00 \%)\left(\mathrm{t}_{(79)}=2.78, \mathrm{p}=0.007\right)$, which might have

708 indeed reflected a motive driven by increased spitelfulness (Jensen 2010). Altogether, the present 
709 data do not conform to the assumption that the spitefulness motive was the only driving force of

710 rejections in case of unfair offers, yet it could have motivated a subgroup of subjects, which

711 needs to be determined by future studies.

712 When looking at the findings of study 1 we found that the minimal group formation task elicited

713 parochial altruism in the same manner as did previous studies with natural groups (e.g., ethnic

714 groups as in Fershtman and Gneezy 2001, or the sample of political supporters tested in study 2).

715 The minimal group formation task resembled previously applied methods of assigning subjects

716 to different groups according to their performance on a meaningless task (like in a task that

717 required the estimation of the number of presented dots). Given previous evidence indicating that

718 even such minimal conditions for group assignment promote an intergroup bias (Brewer 1979;

719 Tajfel et al. 1971; Volz, Kessler, and Cramon 2009), we expected to find a similar pattern. But

720 note that alternative methods to create group identity have also revealed conflicting findings

721 indicating that norm violations committed by ingroup members are punished more often (e.g.,

722 McLeish and Oxoby 2007; Mendoza et al., 2014). Although costly punishment has been

723 proposed to sustain group cooperation (e.g., Fehr and Gächter 2002) and may thus be expected to

724 occur more often in response to unfair ingroup members, we found previously that our version of

725 the intergroup-UG particularly provoked increased punishment of unfair outgroup members by

726 young healthy men, even when our participants played for themselves without a direct intergroup

727 competition (Diekhof, Wittmer, and Reimers 2014; Reimers, Büchel, and Diekhof 2017).

728 Apart from similarities study 1 and study 2 nevertheless also exhibited a difference, namely in

729 the percentage of rejections of unfair proposals per se (study $1>$ study 2 ). This might have been

730 related to differences in aspects of the personality of subjects, that were determined by two self-

731 report questionnaires. For one thing, the participants of study 1 showed a higher degree of 
732 negative reciprocity, which comprised the increased tendency for retaliation or to harm someone

733 who has previously harmed oneself, while the tendency to return a favor (positive reciprocity)

734 and the trust in strangers was reduced in comparison of subjects from study 2. For another, the

735 participants of study 1 were also more impulsive. Impatience as an aspect of impulsiveness has

736 previously been shown to influence decisions in the UG. In particular, spitefulness in the UG

737 may be driven by an increased impatience, which would result in increased rejections of unfair

738 offers as well as reduced proposals in general (Espín et al. 2015). Interestingly, of the 40

739 subjects, who showed no difference in responding to unfair offers from the out- and the ingroup

74030 were from study 1 , which is approximately 50 percent of the sample (see above). This would

741 fit with the observed average personality profile of increased negative reciprocity in combination

742 with heightened impulsivity of the men from study 1, and points in the direction of increased

743 spitefulness as one motive for the exceedingly high rejection rates.

744

$745 \quad 4.2$ Testosterone may modulate parochial altruism in different social contexts

746 The major aim of this research project was to assess the relation between endogenous

747 testosterone and parochial altruism in two related, yet distinct social settings. Taken together, we

748 found only weak, yet consistent evidence for a positive connection between testosterone and the

749 preferential punishment of unfairness in outgroup members in the two studies (see Fig. 3). Not

750 surprisingly this correlation was most visible in subjects who exhibited a more selfish decision

751 strategy (i.e., who did not show a general distaste for unfairness and thus overall high rejection

752 rate, but in contrast exhibited a rather flexible rejection style that also differentiated more

753 between the in- and the outgroup). This might indicate a modulatory role of testosterone on the

754 behavioral expression of male parochial altruism as suggested previously (see also Reimers, 
755 Büchel, and Diekhof, 2017). The effects of testosterone on altruistic punishment in the UG have

756 often been subtle or were even contradictory at times (see introduction). This currently precludes

757 an unequivocal interpretation of the role of testosterone in altruistic punishment in the UG and its

758 interaction with parochialism. For this reason, the present data need to be replicated in other

759 intergroup contexts (e.g., in the comparison of different ethnic groups or in members of different

760 universities). Further, the causal relationship between testosterone and parochial altruism has to

761 be determined by pharmacological intervention studies that ideally test both men and women.

762

763 As it stands, the two employed intergroup paradigms are most comparable to the ones used by

764 Diekhof, Wittmer and Reimers (2014) and by Reimers, Büchel and Diekhof (2017), who also

765 assessed healthy young men. However, the present results do not correspond to our previous

766 findings. In the behavioral study of Diekhof, Wittmer and Reimers (2014) the positive

767 relationship between testosterone and parochial altruism was not observed in the unbiased

768 context, but only occurred when soccer fans transitioned from the neutral session to the

769 competitive part of the intergroup-UG, during which groups explicitly competed for an

770 additional group bonus. This was reflected by the relative enhancement of rejections of rather

771 fair outgroup offers (4:6), which was stronger in soccer fans with a high testosterone level.

772 Moreover, the same subjects showed an increased parochialism bias, but only during the

773 competition, whereas there was no such relationship in the unbiased session of the intergroup-

774 UG. Finally, when being in the role of a proposer, soccer fans with high testosterone made more

775 generous proposals to members of their ingroup, which could not be observed in the present

776 studies. However, our previous and present behavioral studies differ in some important aspects.

777 While in the previous study (Diekhof, Wittmer, and Reimers 2014) participants faced proposers 
778 of four different sports teams (i.e., the soccer ingroup, a neutral soccer outgroup, an unknown

779 cricket outgroup and a disliked soccer outgroup), three of whom were directly competing in the

780 German soccer league (Bundesliga), the present research either used artificially created group

781 identities or employed a natural group of German voters with high political interest. We can only

782 assume that the differences in the groups under research might have led to different degrees of

783 group commitment, as demonstrated previously by Weisel and Böhm (2015). Despite the use of

784 natural groups in both study 2 and the study by Diekhof, Wittmer, and Reimers (2014), who

785 were competing for desired resources, i.e., either for seats in the German Bundestag or a high

786 Bundesliga ranking, we speculate that soccer fandom evokes a much stronger emotional group

787 affiliation than being a supporter of a certain political party prior to an important election in

788 Germany, even though this was not explicitly tested here. Compared to these natural social

789 settings, even less emotional commitment should be assumed in a member of a minimal group

790 that was based on the performance in a simple reaction time task like in study 1, although this

791 assumption is again speculative since it was not tested here. As already discussed in detail by

792 Weisel and Böhm (2015), the election campaigns of the different mainstream parties in Germany

793 (SPD, Greens, $C D U$ and Free Liberals) are less emotional than for example in the United States

794 (US). As Weisel and Böhm (2015) put it, the political discourse in Germany is mild and the

795 mainstream parties are not as polarized as for example the Democrats and Republicans in the US.

796 Also, many voters may consider them to have more in common than in separation. Only parties

797 on the extreme right or left wing may be considered as distinct, which was also demonstrated

798 here by the ranking of the extreme right wing party, the $A f D$. Of the 34 participants of study 2,28

799 categorized the extreme right as rank 6, and another 3 did so as rank 5 . In contrast to interactions

800 between political voters in real life, the context of soccer fandom is characterized by a high 
801 degree of enmity between teams and normally the affiliation with one's own team is very strong

802 and emotional, that it may often resemble a tribal identity (van Vugt and Park 2010). Our

803 previous study only tested subjects who strongly agreed with statements like "soccer is my life"

804 and who owned not only season tickets for matches of their favorite team, but also went to away

805 matches and owned fan merchandise like bedclothes with a team logo (Diekhof, Wittmer, and

806 Reimers 2014). Further, a soccer season comprises 34 weeks of a year with games every

807 weekend, while an election for the German Bundestag happens only every 4 years and the hot

808 phase of the election campaign comprises only a handful of weeks directly before the election.

809 Soccer fandom thus requires a constant engagement with the success of one's favorite team as

810 well as real life interactions with other supporters of one's team as well as those from rival teams

811 (criteria that were all fulfilled by the participants of the study performed by Diekhof, Wittmer,

812 and Reimers 2014). Weisel and Böhm (2015) found less outgroup hate in supporters of political

813 parties than in soccer fans in an economic exchange task, which was also sensitive for the

814 different aspects of parochialism. When comparing the parochialism bias in relation to unfair

815 offers (i.e., the Delta of rejections of unfair offers made by the outgroup minus those from the

816 ingroup) of the present two and our previous behavioral soccer study (Diekhof, Wittmer, and

817 Reimers 2014), we see that the minimal group study 1 had the lowest value (mean \pm standard

818 deviation $=11.3 \% \pm 27.8 \%$, which was lower than the bias found in study 2 (mean \pm standard

819 deviation $=14.1 \% \pm 19.1 \%$ ). In contrast, the parochialism bias documented by Diekhof,

820 Wittmer, and Reimers (2014) when comparing the ingroup and the antagonistic outgroup was

821 much higher (mean \pm standard deviation $=24.8 \% \pm 36.5 \%)$ as was the bias observed in the

822 neuroimaging study by Reimers, Büchel and Diekhof (2017) (mean \pm standard deviation $=$

$82321.7 \% \pm 29.7 \%$ ). Further, even the Delta based on the average of the three outgroups of the 
824 behavioral soccer study (i.e., the antagonistic soccer team, the neutral soccer team, and the

825 unknown cricket team) minus the ingroup rejection rates remained the highest compared to the

826 present two studies (mean \pm standard deviation $=17.6 \% \pm 28.3 \%$ ). Based on this and the

827 observations made by Weisel \& Böhm (2015), we speculate that the emotional engagement

828 might have been highest in the hardcore soccer fans, which could be the reason why we had been

829 unable to observe the rather subtle effect of testosterone on behavior during the unbiased context

830 of the UG there, during which soccer fans already exhibited a very high degree of parochialism

831 per se. Nevertheless, the present result emerged across the two different social settings of study 1

832 and 2, which may point to a valid, but small effect of testosterone on latent behavioral

833 parochialism during socio-economic interactions outside of the context of soccer fandom.

834

835 Finally, we also performed a cued memory recall task in study 2 . We did not find a memory

836 advantage for schema-incongruent information in the given social setting (e.g., for unfair

837 proposals made by ingroup members) as suggested previously (Bell and Buchner 2012; Hechler,

838 Neyer, and Kessler 2016). However, in contrast to these studies group association was not

839 reinstated in the cued recall task, but facial identities were shown without any reference to the

840 group they belonged to. This may explain why the general recall performance ranged around

$84150 \%$ chance level for fair and unfair proposers across ranks (mean \pm sem: hit rate for all fair

842 proposers $=51.3 \% \pm 2.7 \%$; hit rate for all unfair proposers $=48.0 \% \pm 3.0 \%$ ), while the hit rate

843 for new pictures was the highest (mean \pm sem: hit rate for new pictures $=57.5 \% \pm 2.0 \%$ ). We

844 also found a small effect of reduced testosterone on hit rates for fair as compared to unfair

845 proposers (better recall of fair proposers) in the analysis of the estimated marginal means. A

846 recent neuropsychological study with a focus on cue-induced forgetting and recall in relation to 
847 salivary testosterone found something similar, namely that low testosterone levels were

848 associated with improved binding of the newly encoded memories to their context cue (Sterzer et

849 al., 2015). However, since the present effect could not be ascertained in study 1, in which no

850 cued recall test was performed, and did not occur when the complete sample was subdivided by

851 the mean of standardized testosterone (below or above average testosterone), we cannot infer that

852 this was not just a sporadic finding. Future studies have to more carefully assess the interaction

853 of social distance by fairness in larger samples using different cued recall tasks, with or without

854 indicators of group identity.

855

$856 \quad 4.2$ Limitations and future perspective

857 The present studies have several limitations that need to be addressed by future studies. First, 858 sample size, especially that of study 2 , was limited and therefore the power to identify the 859 potentially subtle associations between testosterone and behavior was restricted. Nevertheless, 860 we found similar effects in both studies that also held when combining both data sets.

861 Second, the present studies identified a single hormone as a correlate of parochial altruism in the 862 intergroup-UG. However, testosterone may not be the only hormone involved in ingroup 863 favoritism and outgroup hostility. There is recent evidence for other hormonal systems to play a 864 role in shaping parochial altruism. For instance, the neuropeptide oxytocin has been shown to 865 drive parochial altruism in men during economic interactions (De Dreu et al. 2010). The steroid 866 hormones testosterone and also estrogen have been shown to modulate the expression of the 867 neuropeptides oxytocin and vasopressin (Liening and Josephs 2010; Soares et al. 2010), which 868 are both involved in a variety of social behaviors and economic decision making (Bos et al. 869 2012). Further, another steroid hormone that might potentially influence testosterone's effects on 
870 social behavior is cortisol. A growing number of studies provide evidence for the dual-hormone

871 hypothesis, which states that the effects of testosterone on status-related behavior, such as

872 dominance, depend on the levels of cortisol (Mehta and Josephs 2010). In fact, a recent study has

873 provided initial evidence for the dual-hormone hypothesis in the context of an UG showing that a

874 rise in testosterone was associated with increased acceptance rates of unfair offers in individuals

875 with decreased cortisol levels (Mehta et al. 2015). Yet, the dual-hormone hypothesis has not

876 remained undebated and two recent meta-analyses demonstrate only weak effects (Dekkers et al.,

877 2019; Grebe et al., 2019). These results call for much larger samples for hypothesis testing as

878 well as pre-registered study protocols in the future.

879 Third, another aspect that currently remains unknown, as it was not in the focus of the present 880 study, is the impact of genetic predispositions on individual differences in parochial altruism. For 881 instance, a genetic polymorphism in the androgen receptor gene, the CAG tandem repeat length,

882 is associated with the sensitivity for circulating androgens such as testosterone (Chamberlain, 883 Driver, and Miesfeld 1994). Subjects with a more selfish decision strategy were reported to show

884 a tendency towards shorter repeat lengths and thus supposedly increased androgen sensitivity 885 (Reimers, Büchel, and Diekhof 2017), which would help to explain the present findings of a 886 positive correlation between the parochialism bias and testosterone that was particularly evident 887 in men who showed reduced inequity aversion across groups. Other studies also demonstrated 888 nuanced relationships between personality, repeat length, testosterone and aggression (Geniole et 889 al., 2019), suggesting that genetic predisposition may be an important moderator of the relation 890 between fluctuating hormones and behavior as well as brain physiology.

891 Fourth, the present studies as well as our previous ones (e.g., Diekhof, Wittmer and Reimers, 892 2014) were restricted to men. It thus remains to be determined how women would react to 
893 intergroup manipulations in the UG and whether endogenous testosterone may be related to

894 female parochial altruism. Evolutionary theories of parochial altruism like the one formulated by

895 Choi \& Bowles (2007) or the 'male warrior hypothesis' (van Vugt \& Park, 210) do not make

896 explicit claims about female behavior during group competition or conflict. However, the

897 'steroid/peptide theory of social bonds' (van Anders, Goldey and Kuo, 2011) makes some

898 suggestions regarding the role of testosterone in the achievement of social goals that may also

899 apply for females. Accordingly, in females testosterone may trigger defensive aggression in a

900 special case of social threat, namely when there is a need to protect her offspring against outside

901 threat. One may therefore speculate that women may also show parochialistic behaviors that are

902 related to testosterone, however these might become particularly evident in situations that

903 involve the core ingroup (e.g., family, mother-infant interaction) rather than an abstract group

904 (like in study 1) or a political view (like in study 2). So it remains to be determined by future

905 studies to what extent female testosterone mediates parochialism in general and parochial

906 altruism in particular.

907 Finally, the expression of parochial altruism may not only be driven by physiological factors, but

908 may further be shaped and could even be intensified by cultural ramifications like gender or

909 racial stereotypes, socially preferred or sanctioned behaviors and long-standing rivalries between

910 groups. Yet, by thoroughly assessing the physiological basis of parochial altruism we might be

911 better able to formulate hypotheses that address the potential interaction between physiological

912 and cultural factors that may collectively lead to prevailing intergroup biases and may fuel

913 racism across the globe.

914

915 5. Conclusion

Peer) reviewing PDF | (2019:02:35282:2:0:NEW 19 Jul 2019) 
916 In conclusion, the present findings show that high levels of testosterone are linked to behavioral

917 patterns of parochial altruism depending on individual decision strategy. Extending previous data

918 that demonstrated an association between testosterone and parochial altruism in soccer fans

919 (Diekhof, Wittmer, and Reimers 2014; Reimers, Büchel, and Diekhof 2017; Reimers and

920 Diekhof 2015), the present study revealed a comparable relationship in artificially created groups

921 and supporters of political parties. Based on the concordant findings of study 1 and 2, it may be

922 assumed that the effect of testosterone on parochial altruism represents an evolutionary

923 conserved neurobiological mechanism that is also detectable in minimal group contexts as well

924 as natural social settings outside the context of soccer fandom. In sum, our results add further

925 evidence to the modulatory role of testosterone in shaping parochial altruism and point to

926 potential future avenues for research aiming to understand the neuroendocrinology underlying

927 this prevalent human behavior.

928

929 6. Author contributions

930 LR and ED designed the experiments. Data collection was performed by LS, EK and MY. All

931 authors analyzed the data. ED and LR wrote the first draft of the paper and all authors

932 contributed in revising and finalizing the manuscript.

933

934 7. Acknowledgements

935 We would like to thank A. Kroll for the analysis of hormonal parameters and M. Langbehn for

936 helping with programming the computer-based UG and the analysis batches. In addition, we

937 would like to thank all the anonymous participants of this research project. 


\section{8. References}

940 Amodio, David M., and Chris D. Frith. 2006. "Meeting of Minds: The Medial Frontal Cortex 941 and Social Cognition.” Nature Reviews. Neuroscience 7(4): 268-77.

942 Baumgartner, Thomas, Lorenz Götte, Rahel Gügler, and Ernst Fehr. 2012. "The Mentalizing 943 Network Orchestrates the Impact of Parochial Altruism on Social Norm Enforcement." $944 \quad$ Human Brain Mapping 33(6): 1452-69.

945 Bell, Raoul et al. 2012. "How Specific Is Source Memory for Faces of Cheaters? Evidence for 946 Categorical Emotional Tagging.” Journal of Experimental Psychology: Learning Memory 947 and Cognition 38(2): 457-72.

948 Bell, Raoul, and Axel Buchner. 2009. "Enhanced Source Memory for Names of Cheaters." 949 Evolutionary Psychology 7(2): 147470490900700.

950 http://journals.sagepub.com/doi/10.1177/147470490900700213.

951 Bell, Raoul, and Axel Buchner. 2012. “How Adaptive Is Memory for Cheaters?” Current 952 Directions in Psychological Science 21(6): 403-8.

953 Bernhard, Helen, Urs Fischbacher, and Ernst Fehr. 2006. "Parochial Altruism in Humans." $954 \quad$ Nature 442(7105): 912-15.

955 Bos, Peter A., Jaak Panksepp, Rose-Marie Bluthé, and Jack van Honk. 2012. “Acute Effects of 956 Steroid Hormones and Neuropeptides on Human Social-Emotional Behavior: A Review of 957 Single Administration Studies.” Frontiers in Neuroendocrinology 33(1): 17-35.

958 Bowles, Samuel. 2009. "Did Warfare among Ancestral Hunter-Gatherers Affect the Evolution of 959 Human Social Behaviors?” Science (New York, N.Y.) 324(5932): 1293-98.

960 Brewer, Marilynn B. 1979. "In-Group Bias in the Minimal Intergroup Situation: A Cognitive961 Motivational Analysis.” Psychological Bulletin 86(2): 307-24. 
962 Burnham, Terence C. 2007. "High-Testosterone Men Reject Low Ultimatum Game Offers." 963 Proceedings. Biological Sciences / The Royal Society 274(1623): 2327-30.

964 Chamberlain, Nancy L., Erika D. Driver, and Roger L. Miesfeld. 1994. "The Length and 965 Location of CAG Trinucleotide Repeats in the Androgen Receptor N-Terminal Domain 966 Affect Transactivation Function." Nucleic Acids Research 22(15): 3181-86.

967 Choi, Jung-Kyoo, and Samuel Bowles. 2007. "The Coevolution of Parochial Altruism and War." $968 \quad$ Science (New York, N.Y.) 318(5850): 636-40.

969 Civai, Claudia, Cristiano Crescentini, Aldo Rustichini, and Raffaella Ida Rumiati. 2012.

970 "Equality versus Self-Interest in the Brain: Differential Roles of Anterior Insula and Medial $971 \quad$ Prefrontal Cortex.” NeuroImage 62(1): 102-12.

972 Cueva, Carlos et al. 2017. “Testosterone Administration Does Not Affect Men's Rejections of 973 Low Ultimatum Game Offers or Aggressive Mood." Hormones and Behavior 87: 1-7. 974 Dekker, Tycho, Agelink van Rentergema, Joost A., Meijera, Bren, Popmab, Arne, 975 Wagemakera, Eline, Huizengaa, Hilde M.. 2019. "A meta-analytical evaluation of the dual976 hormone hypothesis: Does cortisol moderate the relationship between testosterone and 977 status, dominance, risk taking, aggression, and psychopathy? Neuroscience and 978 Biobehavioral Reviews 96: 250-271.

979 Diekhof, Esther Kristina, Susanne Wittmer, and Luise Reimers. 2014. "Does Competition Really 980 Bring out the Worst? Testosterone, Social Distance and Inter-Male Competition Shape $981 \quad$ Parochial Altruism in Human Males." PloS One 9(7): e98977.

982 Dohmen, Thomas, Armin Falk, David Huffman, and Uwe Sunde. 2008. "Representative Trust 983 and Reciprocity: Prevalence and Determinants.” Economic Inquiry 46(1): 84-90.

984 Dreher, Jean-Claude et al. 2016. "Testosterone Causes Both Prosocial and Antisocial Status- 
985 Enhancing Behaviors in Human Males.” Proceedings of the National Academy of Sciences $986 \quad 113(41): 11633-38$.

987 De Dreu, Carsten K. W. et al. 2010. "The Neuropeptide Oxytocin Regulates Parochial Altruism 988 in Intergroup Conflict among Humans.” Science (New York, N.Y.) 328(5984): 1408-11.

989 Eisenegger, C. et al. 2010. "Prejudice and Truth about the Effect of Testosterone on Human 990 Bargaining Behaviour.” Nature 463(7279): 356-59.

991 Espín, Antonio M., Filippos Exadaktylos, Benedikt Herrmann, and Pablo Brañas-Garza. 2015.

992 "Short- and Long-Run Goals in Ultimatum Bargaining: Impatience Predicts Spite-Based 993 Behavior." Frontiers in Behavioral Neuroscience 9(August): 1-14.

994 http://journal.frontiersin.org/Article/10.3389/fnbeh.2015.00214/abstract.

995 Fehr, Ernst, and Simon Gächter. 2002. "Altruistic Punishment in Humans.” Nature 415(6868):

$996 \quad 137-40$.

997 Fershtman, Chaim, and Uri Gneezy. 2001. "Discrimination in a Segmented Society: An 998 Experimental Approach.” The Quarterly Journal of Economics 116(1): 351-77.

999 Mendoza, Lane, Amodio 2014. "For Members Only: Ingroup Punishment of Fairness Norm 1000 Violations in the Ultimatum Game.” Social Psychological and Personality Science 5(6): $1001 \quad 662-70$.

1002 Geniole SN, Procyshyn TL, Marley N, Ortiz TL, Bird BM, Marcellus AL, Welker KM, Bonin 1003 PL, Goldfarb B, Watson NV, Carré JM. 2019. Using a Psychopharmacogenetic Approach 1004 To Identify the Pathways Through Which-and the People for Whom-Testosterone Promotes $1005 \quad$ Aggression. Psychol Sci. 30(4): 481-494.

1006 Gintis H, Bowles S, Boyd R, Fehr E 2003. "Explaining altruistic behavior in humans. Evol and $1007 \quad$ Hum Behav 24: 153-172. 
1008 Goette, Lorenz, David Huffman, Stephan Meier, and Matthias Sutter. 2012. "Competition 1009 Between Organizational Groups: Its Impact on Altruistic and Antisocial Motivations.” $1010 \quad$ Management Science 58(5): 1-13.

1011 Grebe, Nicholas M., Del Giudice, Marco, Emery Thompson, Melissa, Nickels, Nora, Ponzi, 1012 Davide, Ziliolif, Samuele, Maestripieri, Dario, Gangestad, Steven W. 2019. „Testosterone, 1013 cortisol, and status-striving personality features: A review and empirical evaluation of the 1014 Dual Hormone hypothesis." Hormones and Behavior 109: 25 -37.

1015 Güth, Werner, Rolf Schmittberger, and Bernd Schwarze. 1982. “An Experimental Analysis of 1016 Ultimatum Bargaining." Journal of Economic Behavior \& Organization 3(4): 367-88.

1017 Hechler, Stefanie, Franz J. Neyer, and Thomas Kessler. 2016. “The Infamous among Us:

1018 Enhanced Reputational Memory for Uncooperative Ingroup Members.” Cognition 157: 11019 13. http://dx.doi.org/10.1016/j.cognition.2016.08.001.

1020 Hennenlotter, Andreas et al. 2005. "A Common Neural Basis for Receptive and Expressive 1021 Communication of Pleasant Facial Affect.” NeuroImage 26(2): 581-91.

1022 Henrich, Joseph et al. 2005. "In Cross-Cultural Perspective: Behavioral Experiments in 15 1023 Small-Scale Societies.” Behavioral and Brain Sciences 28(06): 795-815.

1024 Howard, John W., and Myron Rothbart. 1980. "Social Categorization and Memory for In-Group 1025 and out-Group Behavior.” Journal of Personality and Social Psychology 38(2): 301-10. 1026 Jensen, Keith. 2010. "Punishment and Spite, the Dark Side of Cooperation." Philosophical 1027 Transactions of the Royal Society B: Biological Sciences 365(1553): 2635-50.

1028 Kopsida, Eleni, Jonathan Berrebi, Predrag Petrovic, and Martin Ingvar. 2016. “Testosterone 1029 Administration Related Differences in Brain Activation during the Ultimatum Game.” $1030 \quad$ Frontiers in Neuroscience 10: 66. 
1031 Kubota, Jennifer T. et al. 2013. "The Price of Racial Bias: Intergroup Negotiations in the 1032 Ultimatum Game.” Psychological Science 24(12): 2498-2504.

1033 Liening, Scott H., and Robert A. Josephs. 2010. "It Is Not Just About Testosterone:

1034 Physiological Mediators and Moderators of Testosterone's Behavioral Effects." Social and 1035 Personality Psychology Compass 4(11): 982-94.

1036 Marlowe, Frank W. et al. 2011. "The ‘spiteful' Origins of Human Cooperation.” Proceedings of 1037 the Royal Society B: Biological Sciences 278(1715): 2159-64.

1038 McLeish, Kendra, and Robert Oxoby. 2007. "Identity, Cooperation, and Punishment.” IZA 1039 Discussion Paper (2572).

1040 Mehta, Pranjal H., and Jennifer Beer. 2010. "Neural Mechanisms of the Testosterone-aggression 1041 Relation: The Role of Orbitofrontal Cortex.” Journal of Cognitive Neuroscience 22(10): $1042 \quad 2357-2368$.

1043 Mehta, Pranjal H., and Robert A. Josephs. 2010. “Testosterone and Cortisol Jointly Regulate 1044 Dominance: Evidence for a Dual-Hormone Hypothesis.” Hormones and Behavior 58(5): 1045 898-906.

1046 Mehta, Pranjal H., Shira Mor, Andy J. Yap, and Smrithi Prasad. 2015. "Dual-Hormone Changes 1047 Are Related to Bargaining Performance.” Psychological Science 26(6): 866-76.

1048 Otto, Lukas, and Patrick Bacherle. 2011. "Politisches Interesse Kurzskala (PIKS) - Entwicklung 1049 Und Validierung.” Politische Psychologie 1: 19-35.

1050 Plassmann, Hilke, John O’Doherty, Baba Shiv, and Antonio Rangel. 2008. “Marketing Actions 1051 Can Modulate Neural Representations of Experienced Pleasantness." Proceedings of the $1052 \quad$ National Academy of Sciences 105(3): 1050-54.

1053 Reimers, Luise, Christian Büchel, and Esther K. Diekhof. 2017. "Neural Substrates of Male 
1054

1055

1056

1057

1058

1059

1060

1061

1062

1063

1064

1065

1066

1067

1068

1069

1070

1071

1072

1073

1074

1075

1076

Parochial Altruism Are Modulated by Testosterone and Behavioral Strategy." NeuroImage 156: $265-76$.

Reimers, Luise, and Esther Kristina Diekhof. 2015. “Testosterone Is Associated with Cooperation during Intergroup Competition by Enhancing Parochial Altruism.” Evolutionary Psychology and Neuroscience 9: 183.

Sanfey, Alan G. et al. 2003. "The Neural Basis of Economic Decision-Making in the Ultimatum Game." Science 300(5626): 1755-58.

Soares, Marta C. et al. 2010. "Hormonal Mechanisms of Cooperative Behaviour.” Philosophical Transactions of the Royal Society of London. Series B, Biological Sciences 365(1553): $2737-50$.

Sterzer L, Schabus M, Bäuml KH, Kerschbaum HH. 2015. „Intentional updating in episodic memory: Low testosterone associates with enhanced memory updating." Neuro Endocrinol Lett. 36(3):196-200.

Strombach, Tina et al. 2015. "Social Discounting Involves Modulation of Neural Value Signals by Temporoparietal Junction.” Proceedings of the National Academy of Sciences 112(5): 1619-24. http://www.pnas.org/lookup/doi/10.1073/pnas.1414715112.

Tajfel, Henri. 1982. "Social Psychology of Intergroup Relations.” Ann. Rev. Psychol. 33: 1-39. Tajfel, Henri, M. G. Billig, R. P. Bundy, and Claude Flament. 1971. "Social Categorization and Intergroup Behaviour.” European Journal of Social Psychology 1(2): 149-78.

van Anders SM, Goldey KL, Kuo PX. 2011. "The Steroid/Peptide Theory of Social Bonds: integrating testosterone and peptide responses for classifying social behavioral contexts." Psychoneuroendocrinology 36(9):1265-75. doi: 10.1016/j.psyneuen.2011.06.001.

Van Vugt, Mark, and Justin H Park. 2010. “The Tribal Instinct Hypothesis: Evolution and the 
1077 Social Psychology of Intergroup Relations." In The Psychology of Prosocial Behavior, , 13$1078 \quad 32$.

1079 Volz, Kirsten G., Thomas Kessler, and D. Yves von Cramon. 2009. "In-Group as Part of the 1080 Self: In-Group Favoritism Is Mediated by Medial Prefrontal Cortex Activation.” Social $1081 \quad$ Neuroscience 4(3): 244-60.

1082 Wang, Yiwen et al. 2017. "Ingroup/Outgroup Membership Modulates Fairness Consideration: 1083 Neural Signatures from ERPs and EEG Oscillations.” Scientific Reports 7(June 2016): 11084 10. http://dx.doi.org/10.1038/srep39827.

1085 Weisel, Ori, and Robert Böhm. 2015. “'Ingroup Love’ and 'Outgroup Hate’ in Intergroup 1086 Conflict between Natural Groups.” Journal of Experimental Social Psychology 60: 110-20. 1087 Yamagishi T, Mifune N. 2008. "Does shared group membership promote altruism? Fear, greed, 1088 and reputation." Rat and Soc 20: 5-30.

1089 Yamagishi T, Horia Y, Mifune N, Hashimoto H, Li Y, Shinada M, Miura A, Inukai K, Takagishi 1090 H, and Simunovic D. 2012. "Rejection of unfair offers in the ultimatum game is no 1091 evidence of strong reciprocity." Proc Natl Acad Sci USA 109: 20364-20368.

1092 Zak, PJ. Kurzban R, Ahmadi S, Swerdloff, RS, Park J, Efremidze L, Redwine K, Morgan K, 1093 Matzner W. 2009. "Testosterone Administration Decreases Generosity in the Ultimatum Game." $1094 \quad$ PloS One 4(12): e8330.

1095 Zethraeus N, Kocoska-Maras L, Ellingsen T, von Schoultz B, Lindén Hirschberg A, and 1096 Johannesson M. 2009. “A Randomized Trial of the Effect of Estrogen and Testosterone on 1097 Economic Behavior.” Proceedings of the National Academy of Sciences 106(16): 6535-38. 1098 1099 


\section{Figure legends}

1101

1102 Figure 1: Rejection rates of ingroup and outgroup offers in association with testosterone.

1103 Data are subdivided by testosterone group and study. The low testosterone group comprised

1104 individuals with a standardized testosterone level below the standardized mean (0), whereas the

1105 high testosterone group included the subjects with above-average testosterone. The results of

1106 study 1 indicate that men with low testosterone (A) were less inclined to reject unfair outgroup

1107 offers than men with higher testosterone (B), while the former group showed a parochialism bias

1108 only in response to rather fair offers. Study 2 indicates no clear effect of testosterone on the

1109 parochialism bias, when subdividing the complete sample in two groups with low (C) versus

1110 high (D) testosterone. However the analysis of the estimated marginal means that reflect the

1111 most extreme cases at the high versus low spectrum of testosterone, showed a similar

1112 parochialism bias in high testosterone men as observed in study 1 (see text). Significant

1113 differences (Bonferroni-corrected threshold of $\mathrm{p}<0.025)$ in rejection rates are marked with an 1114 asterisk.

1115

1116 Figure 2: Rejection rates for unfair offers increase with increasing social distance of

1117 political party supporters in study 2. Significant differences are observed between the first

1118 rank, i.e. supporters of one's favorite political party, and the last three ranks $(\mathrm{p} \leq 0.002)$

1119 (Bonferroni-corrected threshold of $\mathrm{p}<0.01$ ).

1120 
1121 Figure 3: Testosterone was positively correlated with the parochialism bias across studies.

1122 Higher endogenous testosterone was significantly associated with higher rejection rates related to 1123 unfair outgroup offers relative to unfair ingroup offers $(n=95 ; r=0.245, p=0.017)$.

1124 


\section{Figure 1}

Figure 1: Rejection rates of ingroup and outgroup offers in association with testosterone.

Data are subdivided by testosterone group and study. The low testosterone group comprised individuals with a standardized testosterone level below the standardized mean (0), whereas the high testosterone group included the subjects with above-average testosterone. The results of study 1 indicate that men with low testosterone $(\mathbf{A})$ were less inclined to reject unfair outgroup offers than men with higher testosterone (B), while the former group showed a parochialism bias only in response to rather fair offers. Study 2 indicates no clear effect of testosterone on the parochialism bias, when subdividing the complete sample in two groups with low (C) versus high (D) testosterone. However the analysis of the estimated marginal means that reflect the most extreme cases at the high versus low spectrum of testosterone, showed a similar parochialism bias in high testosterone men as observed in study 1 (see text). Significant differences (Bonferroni-corrected threshold of $p<0.025$ ) in rejection rates are marked with an asterisk. 
A

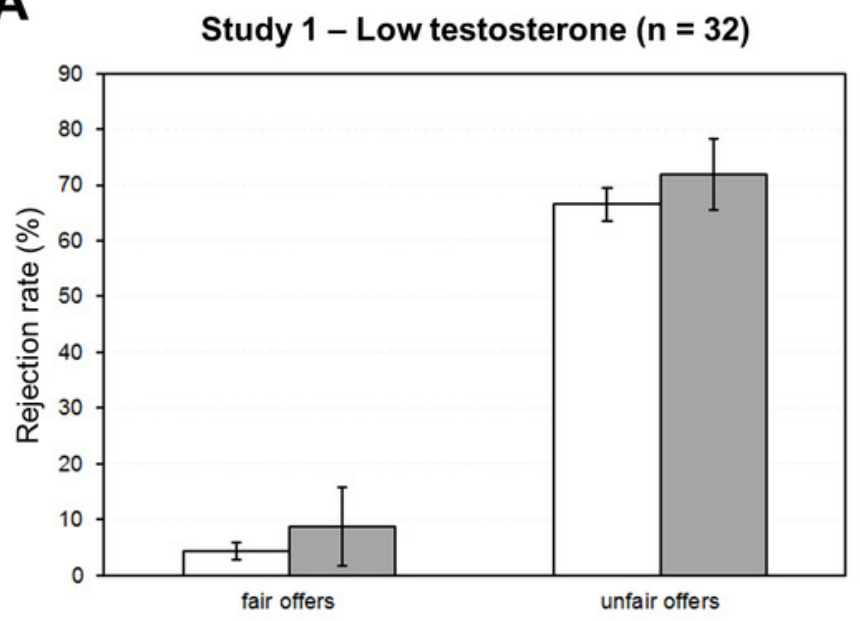

C
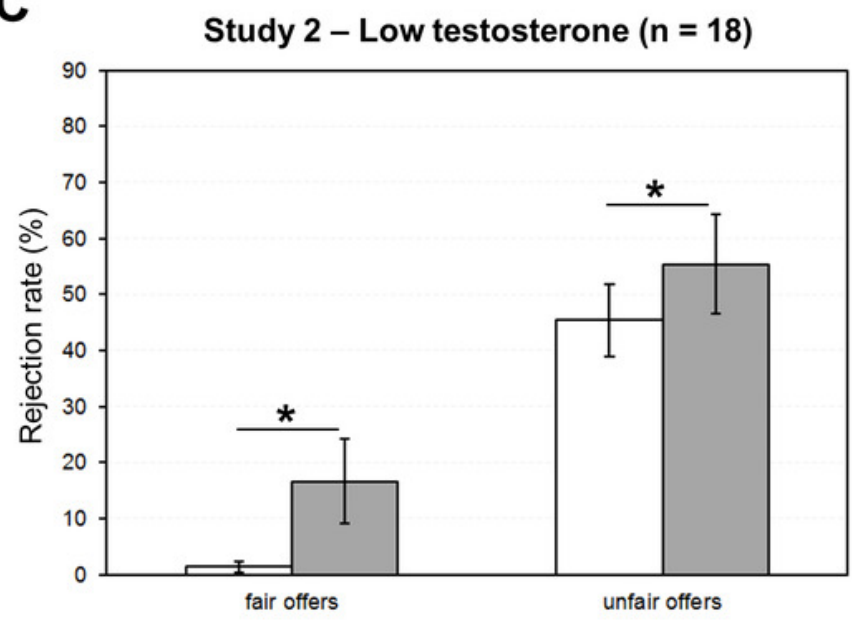

B

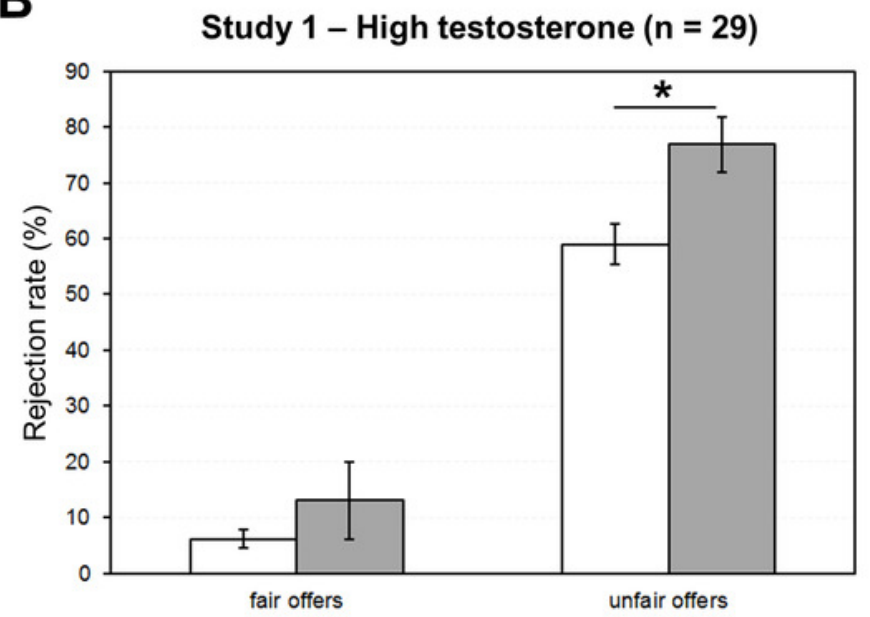

D

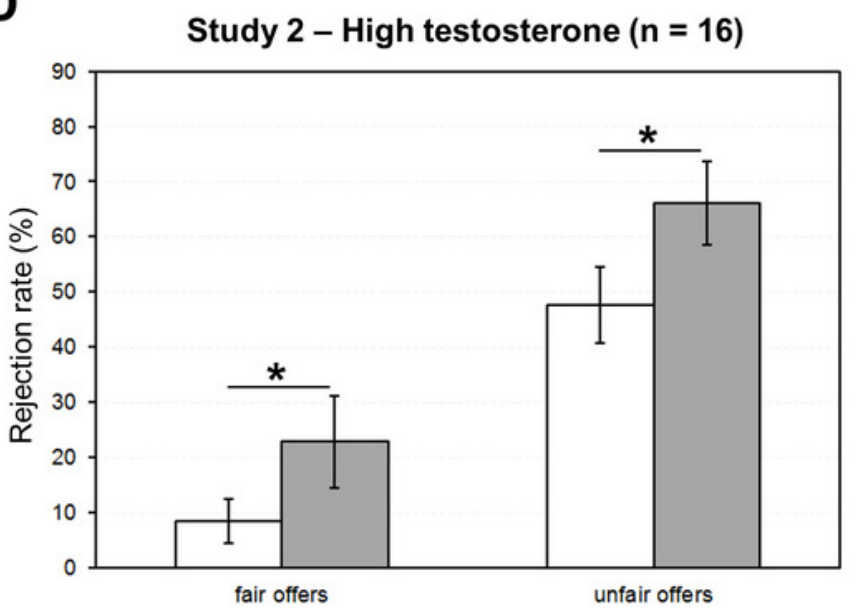

口Ingroup QOutgroup 
Figure 2

Rejection rates for unfair offers increase with increasing social distance of political party supporters in study 2.

Significant differences are observed between the first rank, i.e. supporters of one's favorite political party, and the last three ranks ( $p \leq 0.002$ ) (Bonferroni-corrected threshold of $p<0.01)$.

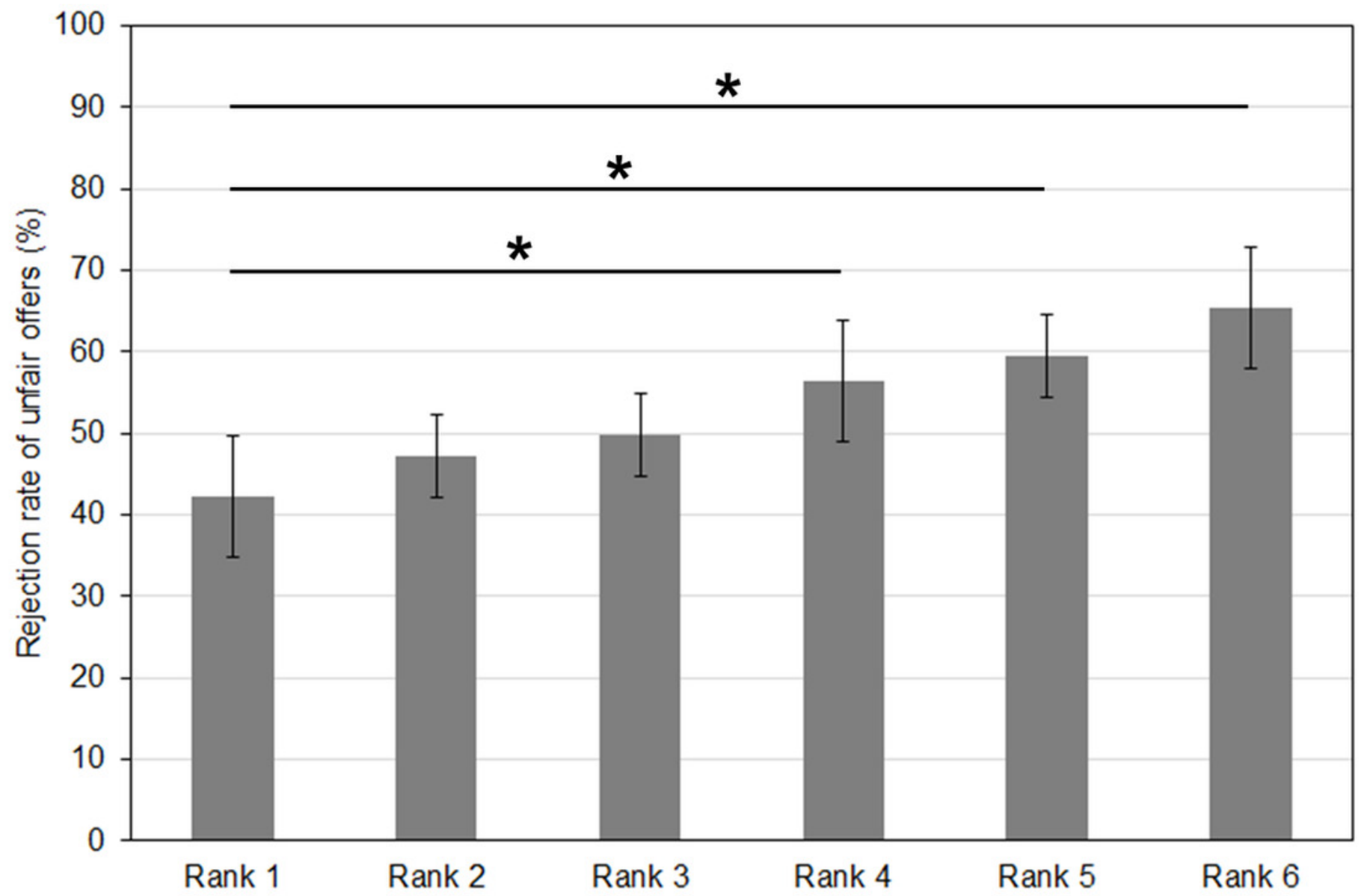


Figure 3

Testosterone was positively correlated with the parochialism bias across studies.

Higher endogenous testosterone was significantly associated with higher rejection rates related to unfair outgroup offers relative to unfair ingroup offers $(n=95 ; r=0.245, p=$ 0.017).

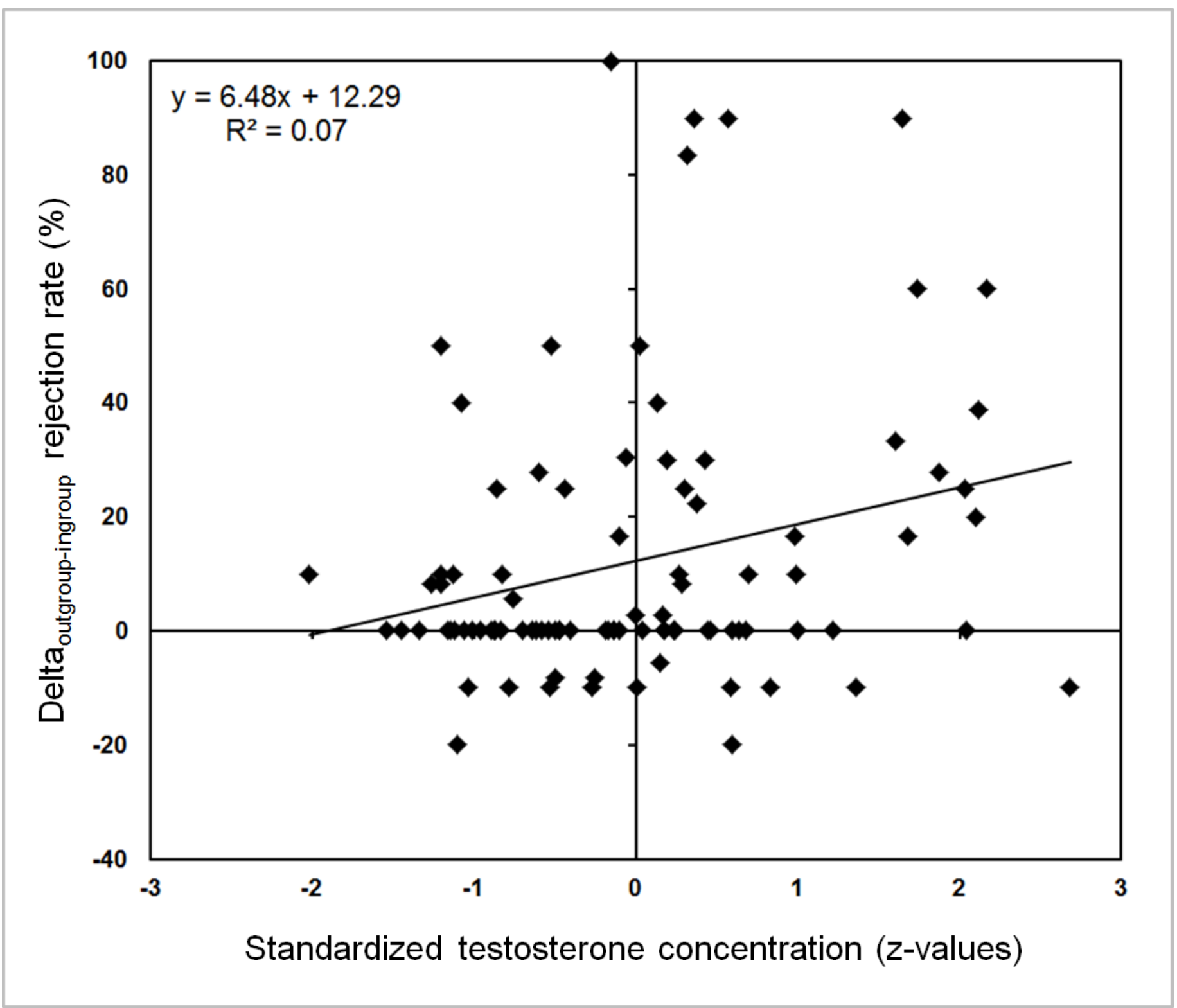




\section{Table 1 (on next page)}

Study 1 - Minimal group design $(n=61)$. Results of the repeated measures ANOVA of rejection rates $(\%)$

*Significant effects $(p<0.05)$ are marked with an asterisk 
1 Table 1:

2 Study 1 - Minimal group design $(n=61)$. Results of the repeated measures ANOVA of rejection rates 3 (\%)

\begin{tabular}{|l|l|l|l|l|}
\hline Main effect or interaction & F-value & df & p-value & ${\text { partial } \text { eta }^{2}}$ \\
\hline Offer* & 194.07 & 1,59 & $<0.001$ & 0.77 \\
\hline Group* & 10.56 & 1,59 & 0.002 & 0.15 \\
\hline z-testosterone & 0.45 & 1,59 & 0.505 & 0.01 \\
\hline Offer x group* & 5.44 & 1,59 & 0.023 & 0.08 \\
\hline Offer x z-testosterone & 0.10 & 1,59 & 0.758 & $<0.01$ \\
\hline Group x z-testosterone & 1.54 & 1,59 & 0.220 & 0.03 \\
\hline Offer x group x z-testosterone* & 7.82 & 1,59 & 0.007 & 0.12 \\
\hline
\end{tabular}

4 *Significant effects $(p<0.05)$ are marked with an asterisk 


\section{Table 2 (on next page)}

Study 2 - Political party supporters $(n=34)$. Results of the repeated measures ANOVA of rejection rates $(\%)$

*Significant effects $(p<0.05)$ are marked with an asterisk 
1 Table 2:

2 Study 2 - Political party supporters $(n=34)$. Results of the repeated measures ANOVA of rejection 3 rates (\%)

\begin{tabular}{|l|l|l|l|l|}
\hline Main effect or interaction & F-value & df & p-value & partial $_{\text {eta }}{ }^{2}$ \\
\hline Offer* & 72.26 & 1,32 & $<0.001$ & 0.69 \\
\hline Group* & 19.83 & 1,32 & $<0.001$ & 0.38 \\
\hline z-testosterone & 0.60 & 1,32 & 0.443 & 0.02 \\
\hline Offer x group & 0.06 & 1,32 & 0.802 & $<0.01$ \\
\hline Offer x z-testosterone & 0.22 & 1,32 & 0.642 & $<0.01$ \\
\hline Group x z-testosterone & 0.99 & 1,32 & 0.327 & 0.03 \\
\hline Offer x group x z-testosterone & 2.81 & 1,32 & 0.104 & 0.08 \\
\hline
\end{tabular}

4 *Significant effects $(p<0.05)$ are marked with an asterisk

5 


\section{Table 3 (on next page)}

Study 2 - Political party supporters $(n=34)$. Results of the repeated measures ANOVA of cued recall hit rate $(\%)$

*Significant effects $(p<0.05)$ are marked with an asterisk 
1 Table 3:

2 Study 2 - Political party supporters $(n=34)$. Results of the repeated measures ANOVA of cued recall 3 hit rate (\%)

\begin{tabular}{|l|l|l|l|l|}
\hline Main effect or interaction & F-value & df & p-value & partial $_{\text {eta }}$ \\
\hline Offer & 1.44 & 1,32 & 0.238 & 0.04 \\
\hline Group & 0.42 & 1,32 & 0.521 & 0.01 \\
\hline z-testosterone & 0.55 & 1,32 & 0.464 & 0.02 \\
\hline Offer x group & 0.04 & 1,32 & 0.846 & $<0.01$ \\
\hline Offer x z-testosterone* & 5.57 & 1,32 & 0.025 & 0.15 \\
\hline Group x z-testosterone & 2.21 & 1,32 & 0.147 & 0.06 \\
\hline Offer x group x z-testosterone & 0.19 & 1,32 & 0.670 & 0.01 \\
\hline
\end{tabular}

4 *Significant effects $(p<0.05)$ are marked with an asterisk

5 


\section{Table 4 (on next page)}

Meta-analysis of combined data from study 1 and $2(n=95)$ - Results of the repeated measures ANOVA of rejection rates (\%) with between subjects factor "study"

*Significant effects $(p<0.05)$ are marked with an asterisk 
1 Table 4:

2 Meta-analysis of combined data from study 1 and $2(n=95)$ - Results of the repeated measures

3 ANOVA of rejection rates (\%) with between subjects factor "study"

\begin{tabular}{|l|l|l|l|l|}
\hline Main effect or interaction & F-value & df & p-value & partial eta $^{2}$ \\
\hline Offer* & 222.29 & 1,92 & $<0.001$ & 0.71 \\
\hline Group* & 29.46 & 1,92 & $<0.001$ & 0.24 \\
\hline z-testosterone & 1.05 & 1,92 & 0.309 & 0.01 \\
\hline study & 1.82 & 1,92 & 0.181 & 0.02 \\
\hline Offer x group & 1.46 & 1,92 & 0.23 & 0.02 \\
\hline Offer x z-testosterone & 0.26 & 1,92 & 0.609 & $<0.01$ \\
\hline Offer x study* & 8.00 & 1,92 & 0.006 & 0.08 \\
\hline Group x z-testosterone & 2.54 & 1,92 & 0.114 & 0.03 \\
\hline Offer x group x z-testosterone* & 10.65 & 1,92 & 0.002 & 0.10 \\
\hline Offer x group x study & 2.59 & 1,92 & 0.111 & 0.03 \\
\hline
\end{tabular}

$4 *$ Significant effects $(p<0.05)$ are marked with an asterisk

5 